\title{
Aletéa Senhorini
}

\section{Dimensões das vias aéreas na asma fatal e na doença pulmonar obstrutiva grave}

Dissertação apresentada à Faculdade de Medicina da Universidade de São Paulo para obtenção do título de Mestre em Ciências

Programa de: Fisiopatologia Experimental Orientadora: Profa. Dra. Thaís Mauad

São Paulo 
Dados Internacionais de Catalogação na Publicação (CIP)

Preparada pela Biblioteca da

Faculdade de Medicina da Universidade de São Paulo

Creprodução autorizada pelo autor

Senhorini, Aletéa

Dimensões das vias aéreas na asma fatal e na doença pulmonar obstrutiva grave / Aletéa Senhorini. -- São Paulo, 2011.

Dissertação(mestrado)--Faculdade de Medicina da Universidade de São Paulo.

Programa de Fisiopatologia Experimental.

Orientadora: Thaís Mauad.

Descritores: 1.Asma/patologia 2.Autopsia 3.Doença pulmonar obstrutiva crônica/patologia 4.Músculo liso/patologia 5.Membrana basal/patologia

USP/FM/DBD-237/11 


\section{DEDICATÓRIA}

Dedico este trabalho ao meu Deus, que sempre me acompanha e encorajara nos momentos de aflição

Aos meus pais, Dorival e Ednalva, pelo incentivo e apoio em todos os momentos da minha vida

Ao meu marido, Emerson por ter me dado alegria e amor Aos familiares e Amigos 


\section{AGRADECIMENTOS}

À Profa. Dra. Thais Mauad, minha orientadora, meu agradecimento especial pela oportunidade de trabalhar neste grupo de pesquisa. Obrigada por todo auxílio e incentivo para que este trabalho se tornasse realidade. Meu apreço e admiração pela sua dedicação e genialidade.

Ao Prof. Dr. Arthur F. Gelb, muito obrigada por ter colaborado com esta pesquisa, e por todo apoio dado em todos os momentos deste trabalho.

Ao grande colaborador para realização deste trabalho o Dr. Luiz Fernando Ferraz da Silva, por sua infinita paciência com minhas dúvidas. Suas contribuições nesta dissertação foram muito valiosas.

À Dra. Cristina Shiang, muito obrigada por ter colaborado com esta pesquisa.

Aos amigos do Grupo Asma: Tatiana Lanças, Diógenes Seraphim 
Ferreira, Bianca Bérgamo Camargo de Araújo, Maína Maria Barbosa Morales, Ruy de Pires Neto, Denise Simão Carnieli, Raquel Annoni, Ana Laura Nicoletti Carvalho, George Castro Figueira de Mello pelo apoio mútuo.

Aos funcionários dos Laboratórios de Histologia e de Imunohistoquímica do Departamento de Patologia da Faculdade de Medicina da Universidade de São Paulo (FMUSP), pelo processamento das lâminas.

Aos funcionários do Serviço de Verificação de Óbito da Faculdade de Medicina da Universidade de São Paulo pelo auxílio na coleta do material.

Ao meu marido, Emerson Rocco Bernardino por ter me dado alegria e amor

À Coordenação de Aperfeiçoamento de Pessoal de Nível Superior (CAPES) pela concessão da bolsa de estudo. 
"Cada pessoa que passa em nossa vida, passa sozinha, é porque cada pessoa é única e nenhuma substitui a outra! Cada pessoa que passa em nossa vida passa sozinha e não nos deixa só porque deixa um pouco de si e leva um pouquinho de nós. Essa é a mais bela responsabilidade da vida e a prova de que as pessoas não se encontram por acaso."

Charles Chaplin 
Esta tese está de acordo com as seguintes normas, em vigor no momento desta publicação:

Referências: adaptado de International Committee of Medical Journals Editors (Vancouver)

Universidade de São Paulo. Faculdade de Medicina. Serviço de Biblioteca e Documentação. Guia de apresentação de dissertações, teses e monografias. Elaborado por Anneliese Carneiro da Cunha, Maria Julia de A. L. Freddi, Maria F. Crestana, Marinalva de Souza Aragão, Suely Campos Cardoso, Valéria Vilhena. 2a ed. São Paulo: Serviço de Biblioteca e Documentação; 2005.

Abreviatura dos títulos dos periódicos de acordo com List of Journals Indexed in Index Medicus. 


\section{Sumário}

Lista de abreviaturas

Lista de tabelas

Lista de figuras

Lista de gráficos

Lista de anexos

Resumo

Summary

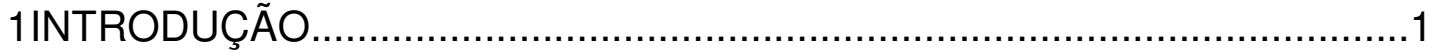

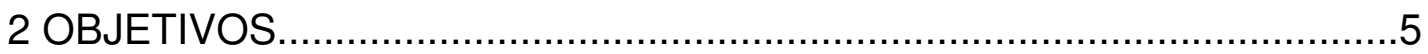

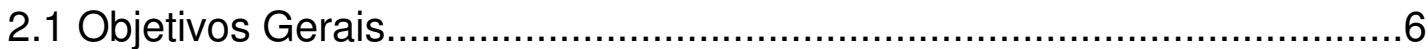

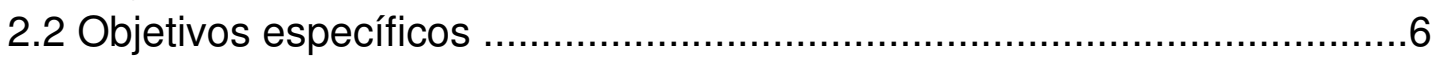

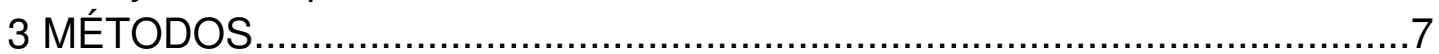

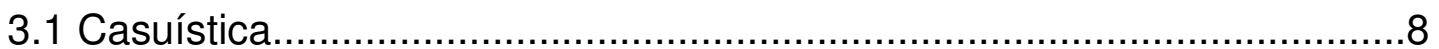

3.1.1 Pacientes falecidos por asma.................................................

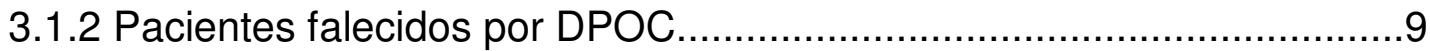

3.1.3 Pacientes controles................................................................... 10

3.2 Processamento tecidual.............................................................. 11

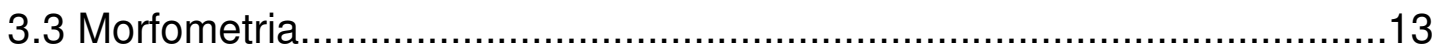

3.4 Análise estatística.....................................................................17

4 RESULTADOS ................................................................................... 19

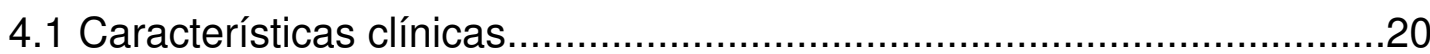

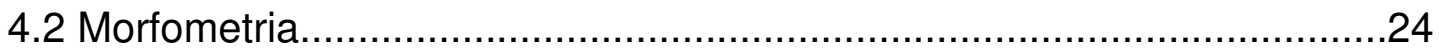

4.2.1 Espessura da membrana basal brônquica........................................25

4.2.2 Dimensões das vias aéreas.........................................................28

4.2.3 Controle adulto versus controle idosos e pré-idosos.........................29

4.3 Controles versus asma fatal e controle versus DPOC, comparados de acordo com a idade.......................................................................

4.3.1 Grupo controle em pacientes adultos versus grupo asma fatal em pacientes adultos.............................................................................

4.3.2 Grupo controle em pacientes pré-idosos e idosos versus grupo asma fatal em pacientes pré-idosos e idosos...............................................32

4.3.3 DPOC versus grupo controle em pacientes idosos............................34

4.4 Grupo asma fatal em pacientes adultos versus grupo asma fatal em

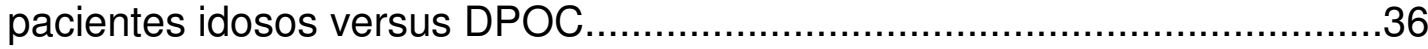

4.5 A influência do uso de corticóides e da idade de início da asma............39

5 DISCUSSÃO............................................................................. 42

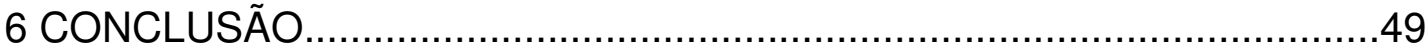

7 ANEXOS

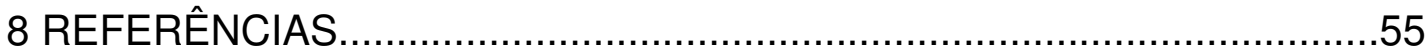




\section{LISTA DE ABREVIATURAS}

\begin{tabular}{|c|c|}
\hline AF & asma fatal \\
\hline AFI & asma fatal em pacientes idosos e pré-idosos \\
\hline ANOVA & análise de variância \\
\hline C & cartilagem \\
\hline CE & camada externa \\
\hline $\mathrm{Cl}$ & camada interna \\
\hline CTRL & controle \\
\hline CTRLA & controles adultos \\
\hline CTRLI & controles idosos e pré-idosos \\
\hline CVF & capacidade vital forçada \\
\hline DLCO & capacidade de difusão do monóxido de carbono \\
\hline DPOC & doença pulmonar obstrutiva crônica \\
\hline $\mathrm{FEV}_{1}$ & volume expiratório forçado no primeiro segundo \\
\hline GSM & glândula submucosa \\
\hline $\mathrm{H} \& \mathrm{E}$ & hematoxilina eosina \\
\hline BALA & broncodilatador de longa ação \\
\hline MB & membrana basal \\
\hline ML & músculo liso \\
\hline NA & não aplicável \\
\hline ND & não disponível \\
\hline SVOC & Serviço de Verificação de Óbito da Capital \\
\hline USP & Universidade São Paulo \\
\hline VAG & via aérea grande \\
\hline VAP & via aérea pequena \\
\hline$\mu \mathrm{m}$ & micrômetro \\
\hline
\end{tabular}




\section{LISTA DE TABELAS}

Tabela 1. Características clínicas dos pacientes com asma fatal e DPOC...23 


\section{LISTA DE FIGURAS}

Figura 1.Fotomicrografia corada a via aérea central de paciente asmático com Movat's pentachrome.

Figura 2 Representação da análise morfométrica realizada para quantificar a espessura da membrana basal das grandes vias aéreas.

Figura 3 Representação da análise morfométrica realizada para quantificar a área da camada interna das grandes e pequenas vias aéreas.

Figura 4 Representação da análise morfométrica realizada para quantificar a área de músculo liso das grandes e pequenas vias aéreas

Figura 5 Representação da análise morfométrica realizada para quantificar a área da camada externa das grandes e pequenas vias aéreas.

Figura 6 Representação da análise morfométrica realizada nas glândulas submucosas das grandes vias aéreas 17

Figura 7. Fotomicrografia das vias aéreas grandes $(A, C$ e $E)$ e das vias aéreas pequenas $(B, D$ e $F)$ de pacientes com asma fatal $(A, B)$, DPOC (C , D) e $(E, F)$ de paciente-controle. 22

Figura 8. Secção longitudinal das grandes vias aéreas de pacientes asmáticos (A), DPOC (B) e pacientes-controle (C). 28 


\section{LISTA DE GRÁFICOS}

Gráfico 1. Espessura da membrana basal $(\mu \mathrm{m})$ das vias aéreas grandes, nos grupos AF em pacientes idosos e controle adultos. 26

Gráfico 2. Espessura da membrana basal $(\mu \mathrm{m})$ nos adultos com asma fatal, pré-idosos com asma fatal e nos pacientes com doença pulmonar obstrutiva grave. 27

Gráfico 3. Área de glândulas submucosas nas grandes vias aéreas nos grupos controle com pacientes adultos e controles em pacientes idosos e pré-idosos. .30

Gráfico 4. Dimensões das grandes vias aéreas do grupo Asma Fatal Adulto e do grupo-controle adulto.

Gráfico 5. Dimensões das pequenas vias aéreas do grupo Asma Fatal Adulto e do grupo-controle adulto. .32

Gráfico 6. Dimensões das grandes vias aéreas do grupo Asma Fatal em pacientes idosos e do grupo-controle em pacientes idosos. .33

Gráfico 7. Área da camada interna, área músculo liso e a área das glândulas submucosas das grandes vias aéreas nos grupos DPOC e controle idoso. 35

Gráfico 8. Dimensões das pequenas vias aéreas do grupo DPOC e do controle idoso. 
Gráfico 9. Espessura da membrana basal das grandes vias aéreas, no subgrupo de 21 pacientes, entre a asma fatal e a DPOC.

Gráfico 10. Área do músculo liso e a área da camada externa das grandes vias aéreas nos grupos AFA, AFI e DPOC

Gráfico 11. Área do músculo liso e a área da camada externa das pequenas vias aéreas nos grupos AFA, AFI e DPOC 


\section{LISTA DE ANEXOS}

Anexo A. Aprovação do Comitê de Ética para a condução da pesquisa:

Protocolo de pesquisa número $844 / 06$.

Anexo B. Tabela das dimensões das vias aéreas na asma fatal, DPOC grave e nos controles. 


\section{RESUMO}

Senhorini A. Dimensões das vias aéreas na asma fatal e na DPOC grave [dissertação]. São Paulo: Faculdade de Medicina, Universidade de São Paulo; 2011.

INTRODUÇÃO: Os pacientes com asma crônica podem compartilhar similaridades clínicas e fisiológicas com pacientes com doença pulmonar obstrutiva crônica, tal como reversibilidade parcial ao broncodilatador ou pouca obstrução persistente do fluxo expiratório. Entretanto, não existem estudos comparando a patologia destas duas doenças em pacientes com idade similares e mesma gravidade da doença. MÉTODOS: Nós comparamos as dimensões das grandes e pequenas vias aéreas de 12

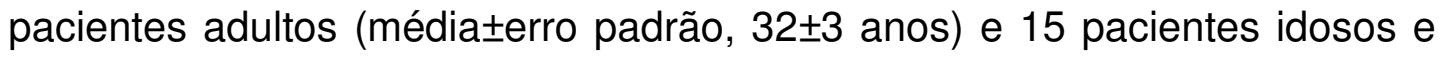

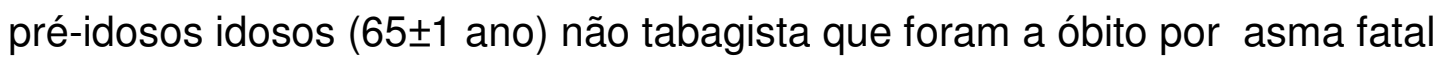
com 14 pacientes tabagistas crônicos que foram a óbito por DPOC grave

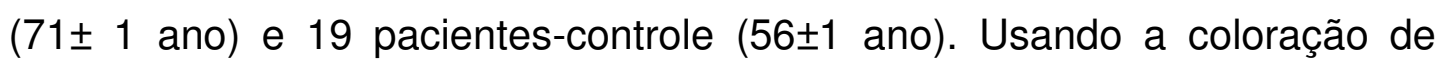
Movat e H\&E, e a técnica de análise de imagens, nós quantificamos a espessura da membrana basal (MB) (valores expressos em $\mu \mathrm{m}$ ) a área de glândula submucosa nas grandes vias aéreas. Nas grandes e pequenas vias aéreas quantificamos a área de camada interna, a área de músculo liso e a área de camada externa. As áreas foram normalizadas pelo perímetro da MB $\left(\mu \mathrm{m} / \mu \mathrm{m}^{2}\right)$. RESULTADOS: os pacientes asmáticos adultos apresentaram a MB, área de músculo liso e a área da camada externa nas grandes e pequenas vias aéreas mais espessas, quando comparadas com os controles com idade similar com DPOC grave. Nos pacientes idosos e pré-idosos com asma, houve uma sobreposição na espessura da MB e na área da glândula submucosa, enquanto que nas pequenas e grandes vias aéreas a área de músculo liso foi mais espessa quando comparados com os controles com idade similar com pacientes com DPOC grave. Os pacientes com DPOC apresentaram nas pequenas e grandes vias aéreas as áreas de músculo liso menor quando comparada aos controles com idade similar. Os asmáticos 
adultos apresentaram a área de músculo liso maior quando comparada aos asmáticos idosos. CONCLUSÃO: Nossos dados fornecem novas informações sobre as mudanças patológicas que podem nos ajudar a entender melhor as similaridades e diferenças patológicas no pacientes adultos e idosos com asma comparados ao DPOC.

Descritores: Asma/patologia, autopsia, doença pulmonar obstrutiva crônica/patologia, músculo liso/patologia, membrana basal/patologia. 


\section{SUMARY}

Senhorini A. Airway dimensions in fatal asthma and severe COPD [dissertation]. São Paulo: "Faculdade de Medicina, Universidade São Paulo"; 2011.

Background: In some patients with chronic asthma, clinical and physiological similarities with chronic obstructive pulmonary disease may co-exist, such as partial reversibility to bronchodilators despite persistent expiratory airflow obstruction. However, pathologic analyses comparing both diseases in patients of similar age and disease severity are scarce.

Methods: We compared the large and small airway dimensions in 12 younger (mean $\pm S D$, age $32 \mathrm{yr} \pm 3 \mathrm{yr}$ ) and 15 older $(65 \mathrm{yr} \pm 1 \mathrm{yr}$ ) non-smoking fatal asthmatics with 14 chronic smokers with severe, fatal COPD (71 yr $\pm 1 \mathrm{yr})$ and 19 control patients (56 yr $\pm 1 \mathrm{yr}$ ). Using H\&E, Movat's pentachrome staining and image analysis, we quantified large airway basement membrane (BM) thickness $(\mu \mathrm{m})$; submucosal gland area; and large and small airway inner wall, smooth muscle and outer wall areas. Areas were normalized by BM perimeter $\left(\mu \mathrm{m}^{2} / \mu \mathrm{m}\right)$.

Results: Younger adult fatal asthmatics had thicker BM, smooth muscle, and outer wall areas in both small and large airways when compared to agematched controls and fatal COPD patients. In older asthmatics, there was an overlap in BM thickness and submucosal gland area, whereas both large and small airway smooth muscle areas were thicker compared to age-matched controls and fatal COPD patients. COPD patients had thinner large and small 
airway smooth muscle areas compared to age-matched controls. Younger asthmatics had thicker small airway smooth muscle area compared to older asthmatics.

Conclusion: Our data provide novel pathological substrate changes that may help us better understand physiological similarities and differences in younger and older patients with asthma compared to COPD.

Descriptors: Asthma/pathology, autopsy, chronic obstructive pulmonary disease/pathology, smooth muscle/ pathology, basement membrane/pathology. 
1 INTRODUÇÃO 


\section{INTRODUÇÃO}

A asma e a doença pulmonar obstrutiva crônica (DPOC) são doenças frequentes das vias aéreas, cursando com limitação ao fluxo expiratório, associadas à significante morbidade e mortalidade. ${ }^{1,2}$

A asma é classicamente ligada à obstrução reversível das vias aéreas cursando com, hiper-responsividade, atopia, eosinofilia e boa resposta ao uso de broncodilatadores. ${ }^{3} \mathrm{Na}$ DPOC, a obstrução ao fluxo aéreo não é completamente reversível e é progressiva. Existe uma hiper-responsividade variável, o fator etiológico mais comum é o tabagismo, existe a presença de neutrofilia e resposta variável ao uso de broncodilatadores é variável. ${ }^{4}$

Do ponto de vista anátomo-patológico a asma e a DPOC são doenças inflamatórias crônicas que atingem a árvore brônquica, estendendo-se para o parênquima pulmonar. ${ }^{5,6}$ Normalmente, os pacientes com DPOC são mais velhos que os asmáticos, mas existe uma população de asmáticos idosos não fumantes, usualmente com doença de início tardio, que frequentemente apresentam similaridades clínicas e funcionais com os pacientes com DPOC. A reação crônica à injúria e o subsequente reparo anormal ocorrem de uma maneira limitada dos pulmões. Essas duas doenças inflamatórias poderiam, em alguns pacientes, estar associadas a alterações estruturais similares nas vias aéreas, por exemplo, com um padrão similar de espessamento/fibrose. $\mathrm{Na}$ ausência de enfisema significante, essas alterações similares podem explicar o porquê de 
similaridades radiológicas, clínicas e fisiológicas estarem presentes nesse subgrupo de pacientes mais velhos. ${ }^{5,6}$

Acredita-se que a estrutura da via aérea tenha um papel importante e determinante na mecânica dessa mesma via. ${ }^{7}$ Alterações intrínsecas dos componentes estruturais dos pulmões, como deposição de componentes da matriz extracelular e presença de infiltrado inflamatório nos pacientes com asma e DPOC alteram a estrutura das vias aéreas. ${ }^{8}$ Por exemplo, o espessamento do músculo liso das vias aéreas na asma, tem um papel importante na patogênese da doença. Existem revisões comparativas sobre os aspectos patológicos da asma e da DPOC, destacando as similaridades e diferenças nos padrões inflamatórios e do remodelamento. ${ }^{5,6,9,10}$ Entretanto, poucos estudos compararam as alterações estruturais dos pacientes asmáticos e dos pacientes com DPOC com a mesma gravidade da doença ou estenderam as observações para grandes e pequenas vias aéreas. ${ }^{11}$

As alterações estruturais pulmonares relacionadas à idade podem possivelmente influenciar na patofisiologia da doença nos pacientes idosos com asma e DPOC. Em pacientes idosos, as alterações do parênquima pulmonar, tal como dilatação dos espaços aéreos e perda das fibras elásticas, já foram descritas, mas ainda há uma escassez de dados sobre o efeito do envelhecimento sobre as estruturas das vias aéreas em adultos humanos. $^{12,13}$

Partindo dessas observações, nos hipotetizamos que os pacientes asmáticos mais velhos têm alterações estruturais das vias aéreas 
semelhantes à de pacientes com DPOC. Neste trabalho, Comparamos as dimensões das vias aéreas em tecido pulmonar proveniente de autópsia de três grupos de estudos: pacientes adultos não fumantes falecidos por asma, divididos em dois grupos de acordo com a sua idade (idosos e pré-idosos), e pacientes com DPOC grave. Os dados foram comparados a um grupocontrole de pacientes autopsiados, também agrupados de acordo com a idade. 
2 OBJETIVOS 


\section{OBJETIVOS}

\subsection{Objetivos Gerais}

Comparar as alterações estruturais das vias aéreas em pacientes adultos que vieram a óbito por asma e DPOC grave, agrupados de acordo com a idade.

\subsection{Objetivos Específicos}

Quantificar a espessura da camada interna, do músculo liso, da camada externa e da camada glandular das vias aéreas grandes e pequenas no tecido pulmonar de pacientes que vieram a óbito por asma fatal e DPOC grave e comparar com indivíduos falecidos por causas outras que não pulmonares.

Comparar as dimensões das vias aéreas em pacientes que faleceram de causas não pulmonares (controles) em indivíduos adultos, idosos e pré-idosos. 
3 MÉTODOS 


\section{MÉTODOS}

O presente estudo foi aprovado pela comissão de Ética do Hospital das Clínicas da Faculdade de Medicina da Universidade de São Paulo Protocolo de pesquisa número 844/06 (Anexo A).

Parte da população do presente estudo foi descrita previamente (Mauad et al., 1999; Mauad at al., 2004; De Medeiros et al., 2005; De Magalhães et al., 2005) em outros estudos do Grupo de Patologia Pulmonar da Faculdade de Medicina da Universidade de São Paulo.

\subsection{Casuística}

\subsubsection{Pacientes falecidos por asma}

Os tecidos pulmonares foram obtidos de indivíduos autopsiados no Serviço de Verificação de Óbitos da Capital (SVOC) da Universidade de São Paulo entre os anos de 1996 e 2004.

Todos os indivíduos morreram por uma crise aguda de asma (asma fatal, AF) eram não fumantes e não apresentavam outra doença pulmonar. Nos achados macroscópicos havia hipersecreção e hiperinsulflação

pulmonar. Microscopicamente, as espécimes pulmonares apresentavam descamação epitelial, espessamento da membrana basal, hiperplasia de 
glândulas submucosas, hipertrofia de músculo liso e inflamação da mucosa com ou sem eosinófilos. Todos apresentavam história pregressa de asma, documentada por questionário aplicado por uma assistente social aos familiares dos indivíduos ou por registros médicos, quando disponíveis. Os dados clínicos obtidos foram: idade de início e duração da asma e tratamento, incluindo o uso de corticóides e hospitalização prévia ao óbito. A asma de início precoce foi definida como aquela que se iniciou antes dos 12 anos de idade. ${ }^{14}$

Os pacientes com AF foram divididos em dois grupos de acordo com a idade ao óbito: asma fatal em pacientes adultos (AFA), que abrange os pacientes falecidos entre 15 e 49 anos de idade, e asma fatal em pacientes idosos e pré-idosos (AFI), que abrange os pacientes que faleceram entre 56 e 78 anos de idade. ${ }^{15,16}$

\subsubsection{Pacientes falecidos por DPOC}

Os tecidos pulmonares foram obtidos de 14 indivíduos que vieram a óbito por DPOC e foram submetidos a autópsia no Lakewood Regional Medical Center - Califórnia, entre os anos de 1994 e 2002. Os pacientes tinham histórico de tabagismo crônico, sem presença de atopia, sem história de asma ou rinite alérgica, com limitação do grave do fluxo aéreo. Vieram a óbito por uma exacerbação aguda da doença ou falência respiratória sem 
pneumonia ou câncer de pulmão. Todos os pacientes tiveram sintomas clínicos por aproximadamente 10 anos e taxa de exacerbação de $2 \pm 0,4$ anos. Os dados disponíveis incluíram intervenção terapêutica, como o uso de corticóide oral e inalatório. A última prova de função pulmonar foi obtida pelo menos 6 meses antes do óbito, quando ainda se apresentavam clinicamente estáveis. $O$ teste de função pulmonar foi realizado com e sem o uso de broncodilatador. As respostas pós-broncodilatador ao uso de 2 puffs do broncodilatador albuterol (180 $\mathrm{mcg}$ ) foram $<200 \mathrm{ml} \mathrm{e}<12 \%$ em todos os pacientes com DPOC. A extensão e a distribuição do enfisema em toda a espécie pulmonar foi insulflada a $25 \mathrm{cmH} 2 \mathrm{O}$. Antes da fixação foi realizada a avaliação do enfisema pela técnica de Thurlbeck. ${ }^{17}$

\subsubsection{Pacientes Controles}

Os tecidos pulmonares foram provenientes do Serviço de Verificação de Óbito da Capital (SVOC), da Universidade de São Paulo. Foram incluídos 19 indivíduos que vieram a óbito por causas não pulmonares, sem histórico de tabagismo, asma ou DPOC e que não apresentaram alterações pulmonares ao exame anátomo patológico. Os pacientes controles foram divididos em dois grupos de acordo com a idade do óbito. No grupo Controles Adultos (CTRLA) foram incluídos pacientes que vieram a óbito entre 44 e 55 anos de idade e no grupo Controles idosos e pré-idosos 
(CTRLI) foram incluídos pacientes que vieram a óbito entre 57 e 79 anos de idade.

\subsection{Processamento Tecidual}

Fragmentos de tecido pulmonar foram coletados das áreas centrais e periféricas, fixados em formaldeído a $4 \%$ por 24 e 48 horas e emblocados em parafina. Cortes de $5 \mu \mathrm{m}$ de espessura foram submetidos à coloração de Hematoxilina e Eosina (H\&E) para identificar a presença de vias aéreas adequadas para análise e para realizar as medidas da espessura da membrana basal (MB). A técnica do Movat pentachrome, previamente utilizada por Hogg et al., foi utilizada para quantificar os diferentes compartimentos das vias aéreas. (Figura 1$)^{18}$ 


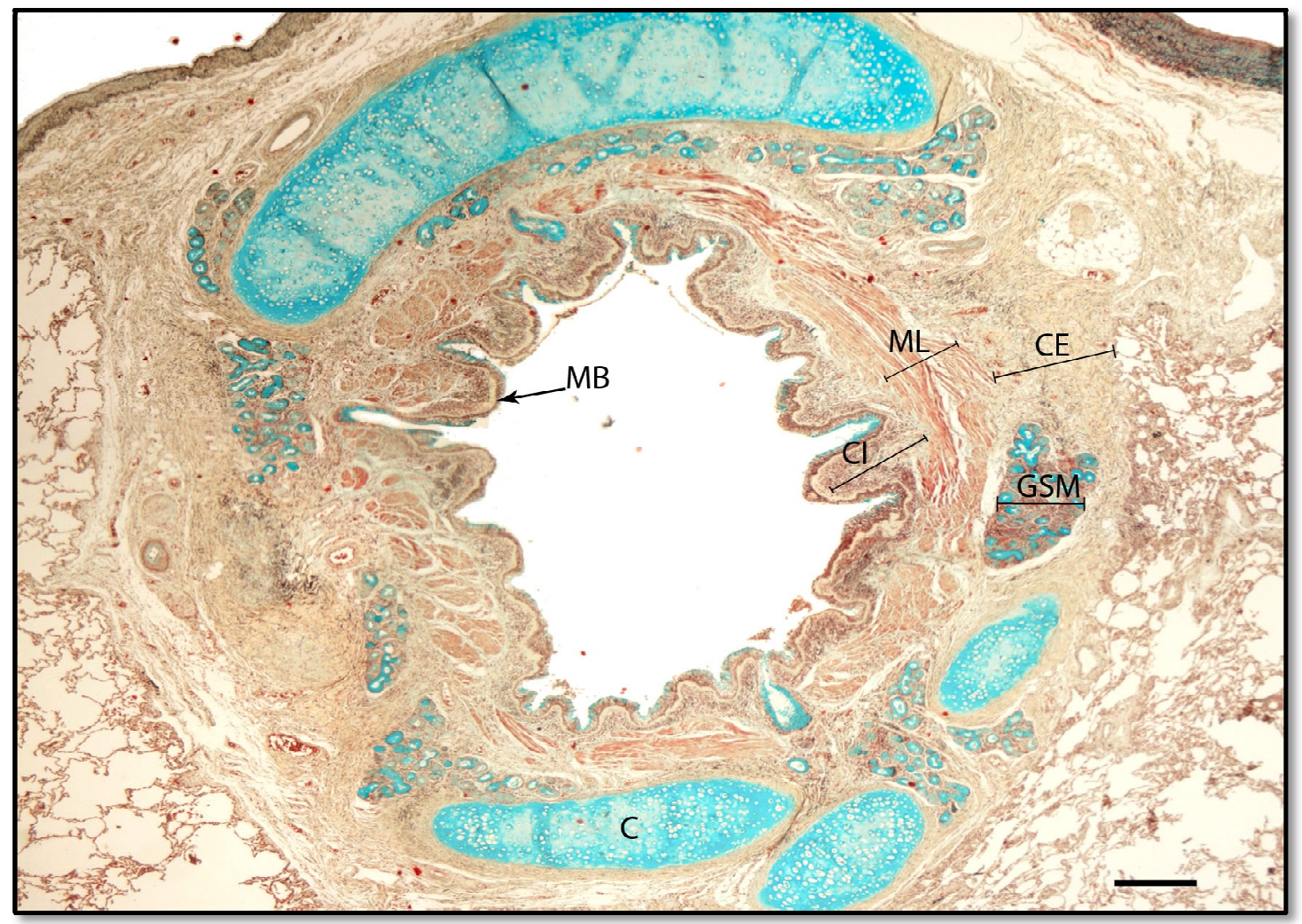

Figura 1. Fotomicrografia mostrando a via aérea grande de paciente asmático corada com Movat's pentachrome. A cartilagem e as células mucosas estão coradas em azul, o músculo é corado em vermelho, a elastina é corada em preto púrpuro e o tecido conjuntivo é corado em amarelo. Os compartimentos analisados foram: camada interna (CI), músculo liso (ML), área de glândulas submucosas (GSM) e camada externa (CE), membrana basal (MB). A barra de escala da imagem corresponde a $250 \mu \mathrm{m} . \mathrm{C}=$ cartilagem 


\subsection{Morfometria}

As imagens foram analisadas a partir do software Image-Pro ${ }^{\circledR}$ Plus 4.1 para Windows ${ }^{\circledR}$ (Media Cybernetics - Silver Spring, MD, USA), em um computador pessoal acoplado a uma câmera de vídeo (JVC TK-C1380 Color Video Câmera, Victor Company of Japan Limited, Japan) que captura imagens de um microscópio óptico Leica DMR (Leica Microsystems Wetzlar $\mathrm{GmbH}$, Wetzlar, Germany). ${ }^{19} \mathrm{Em}$ cada caso foram analisadas duas vias aéreas grandes e três vias aéreas pequenas cortadas transversalmente ${ }^{17}$, classificadas de acordo com o perímetro da membrana basal epitelial (Pmb), sendo considerada via aérea grande, VAG, Pmb $>6 \mathrm{~mm}$, e via aérea pequena, $\mathrm{VAP}, \mathrm{Pmb}<6 \mathrm{~mm}$.

A quantificação da espessura da MB foi realizada nas vias aéreas grandes com os fragmentos pulmonares que foram corados pelo H\&E. Para calcular a espessura da MB de cada via aérea, foram medidos 15 campos consecutivos num aumento de 400x em torno da via. Em cada campo foi delineado manualmente a borda interna e o externo por um determinado comprimento, sendo evitadas as áreas com corte tangencial. A ferramenta "curva de espessura" disponível no programa de imagem Image Pro plus realiza medidas sequenciais entre duas distâncias delineadas acima e abaixo da MB e apresenta a espessura média entre os dois pontos, o resultado final foi a média dos 15 campos em cada via aérea. As medida foram expressas em micrômetros $(\mu \mathrm{m})$. (Figura 2). 


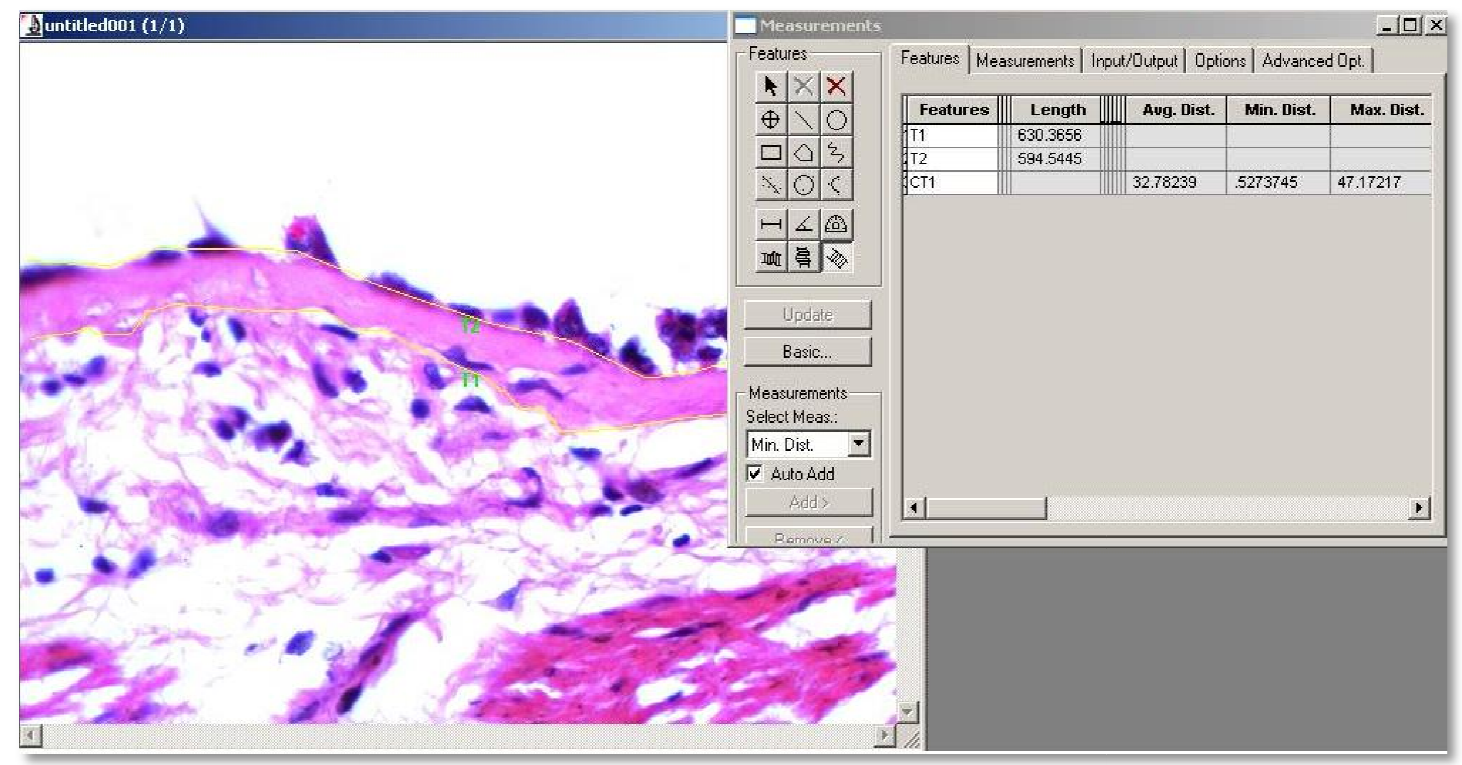

Figura 2 - Representação da análise morfométrica usada na quantificação da espessura da membrana basal epitelial nas grandes vias aéreas.

As seguintes estruturas das vias aéreas foram analisadas nas grandes e pequenas vias aéreas: camada interna $(\mathrm{CI})$, músculo liso $(\mathrm{ML})$, camada externa (CE) e área das glândulas (GSM), esta última somente nas vias aéreas grandes. (Figuras 3,4,5,6 e 7 ). 


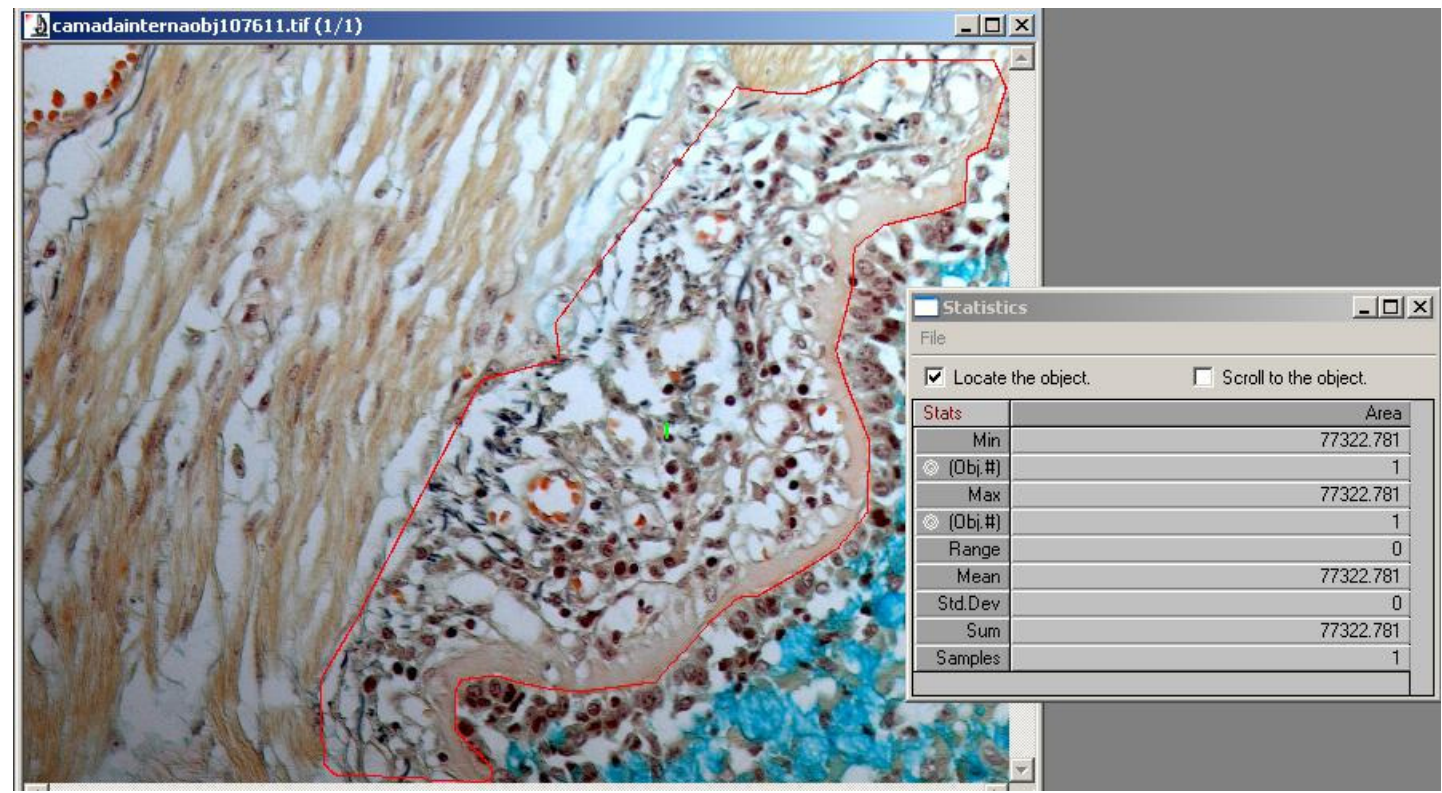

Figura 3 - Representação da análise morfométrica usada na quantificação da área da camada interna nas grandes e nas pequenas vias aéreas

A área de camada interna foi definida como aquela localizada entre 0 epitélio brônquico e a borda interna do músculo liso, incluindo a $\mathrm{MB}$ e a lâmina própria. A área de parede externa foi definida como aquela localizada entre o bordo externo do ML e a borda mais externa da adventícia. A área de $\mathrm{ML}$ e a área das glândulas foram delineadas manualmente ao longo de toda a via área. As circunferências das vias aéreas foram analisadas nos aumentos de 100x a 400x, e seus valores expressos como área corrigidos pelo perímetro da MB correspondente $\mu \mathrm{m}^{2} / \mu \mathrm{m} .{ }^{18}$ 


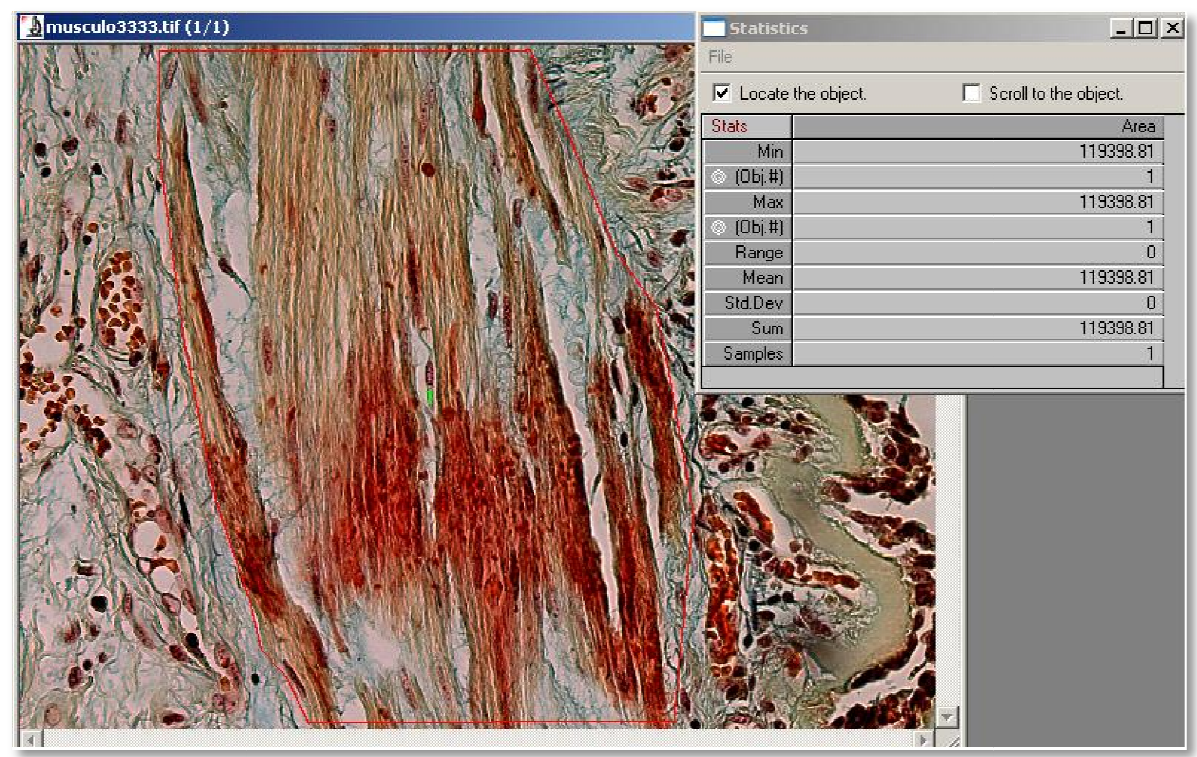

Figura 4 - Representação da análise morfométrica usada na quantificação da área de músculo liso nas grandes e nas pequenas vias aéreas

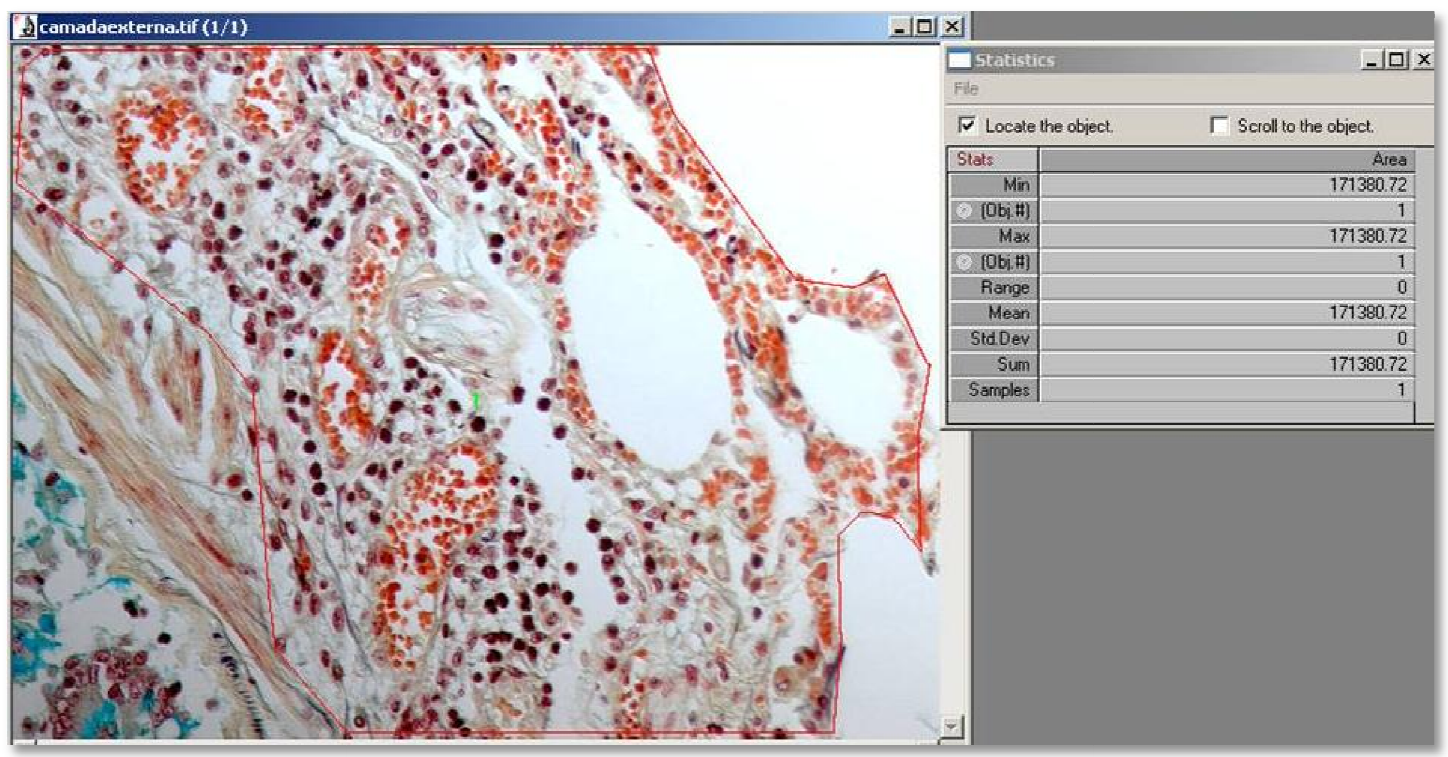

Figura 5 - Representação da análise morfométrica usada na quantificação da área da camada externa nas grandes e nas pequenas vias aéreas 


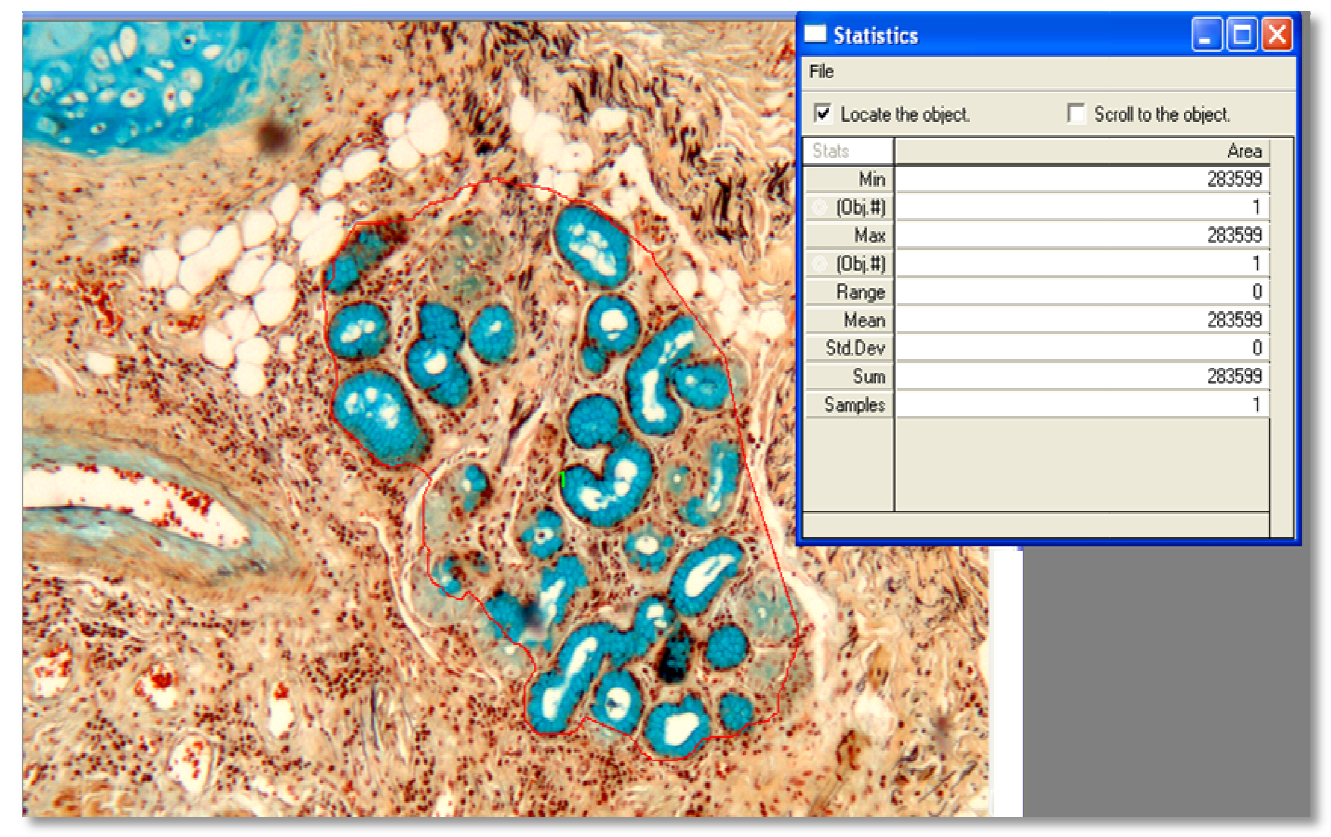

Figura 6 - Representação da análise morfométrica usada na quantificação da área das glândulas submucosa nas grandes vias aéreas.

\subsection{Análise estatística}

Os dados foram expressos como média \pm erro padrão ou mediana e interquartis, dependendo da distribuição dos dados. Os valores de $p$ menor que 0,05 foram considerados significantes em todos os testes aplicados neste estudo. Os valores categóricos foram calculados pelas médias do teste de chi-square. 
Para a análise dos diferentes grupos de doenças com o controle, foi realizado o Test $\mathrm{T}$ ou o teste de Mann Witnney.

$\mathrm{Na}$ comparação entre os grupos de doenças, foram utilizados os testes realizados ANOVA e Kruskal Wallis, seguidos do teste de post hoc de Bonferroni, que foi utilizado para discriminar as diferenças entre os grupos.

As correlações entre os parâmetros clínicos e de morfometria foram realizadas utilizando-se os testes de Pearson ou Spearman.

O programa estatístico utilizado para a análise dos dados foi 0 software Statistical Package for de Social Sciences (SPSS) 15.0 (Chicago, Illinois). 
4 RESULTADOS 


\section{RESULTADOS}

\subsection{Características Clínicas}

As características clínicas dos pacientes falecidos por asma fatal, DPOC e pacientes controles são apresentadas na Tabela 1.

Foram incluídos no estudo 27 pacientes (sendo 21 mulheres) não fumantes que vieram a óbito por uma exacerbação aguda da asma. A média \pm erro padrão e os intervalos das idades foram $51 \pm 4$ (15-78) anos, a média da duração da asma foi $26 \pm 3$ (3-67) anos, a idade de início da asma foi $20 \pm 4$ (1-49) anos. Os paciente asmáticos foram divididos de acordo com a idade do óbito em 12 Asma Fatal em pacientes Adulto (AFA), a média \pm erro padrão e os intervalos das idades foram 32 \pm 3 (15-49) anos e 15 Asma Fatal em pacientes idosos e pré-idosos $(\mathrm{AFI})$ e a média \pm erro padrão e os intervalos das idades foram $65 \pm 1$ (56-78) anos. Na autópsia, todos os pacientes asmáticos tiveram alterações macroscópicas e histológicas compatíveis com asma, incluindo hiperinsulflação, hipersecreção de muco, descamação epitelial, espessamento da $M B$, espessamento do $M L$ e inflamação de mucosa com ou sem presença de eosinófilos. Todas as mortes foram atribuídas ao estado de mal asmático pelos patologistas. (Figura 7). 
No grupo DPOC foram incluídos 14 pacientes, sendo 6 homens, todos ex-fumantes que vieram a óbito por uma exacerbação da doença ou por falência respiratória. A média \pm erro padrão e os intervalos de idade foram $71 \pm 1$ (59-79) anos (Tabela 1). Á autópsia, todos os pacientes tiveram alterações compatíveis com DPOC mostrando enfisema extenso, distorção da parede brônquica, metaplasia de células caliciformes e escamosas do epitélio brônquico, leve a moderada inflamação neutrofílica e linfocítica nas vias aéreas. Não havia broncopneumonia ou câncer de pulmão secundário nas amostras (Figura 7).

grupo-controle consistiu de 19 pacientes, sendo 12 homens, todos não fumantes. A média erro padrão e o intervalo das idades foram $56 \pm 1$ (44-79) anos. Dez casos foram classificados como controle adulto (CTRLA), com média e taxa de idade $49 \pm 1$ (44-55) anos. Nove casos foram incluídos como controles idosos e pré-idosos (CTRLI), com média e taxa de idade $63 \pm 1$ (57-79) anos. As causas das mortes do CTRLA foram: infarto agudo do miocárdio (5 pacientes) e edema agudo de pulmão (5 pacientes). No grupo CTRLI, as causas das mortes foram: infarto agudo do miocárdio (4 pacientes), câncer de útero (1 paciente), esclerose lateral amiotrófica (1 paciente), edema de pulmão (1 paciente), pancreatite (1 paciente). Figura 7 


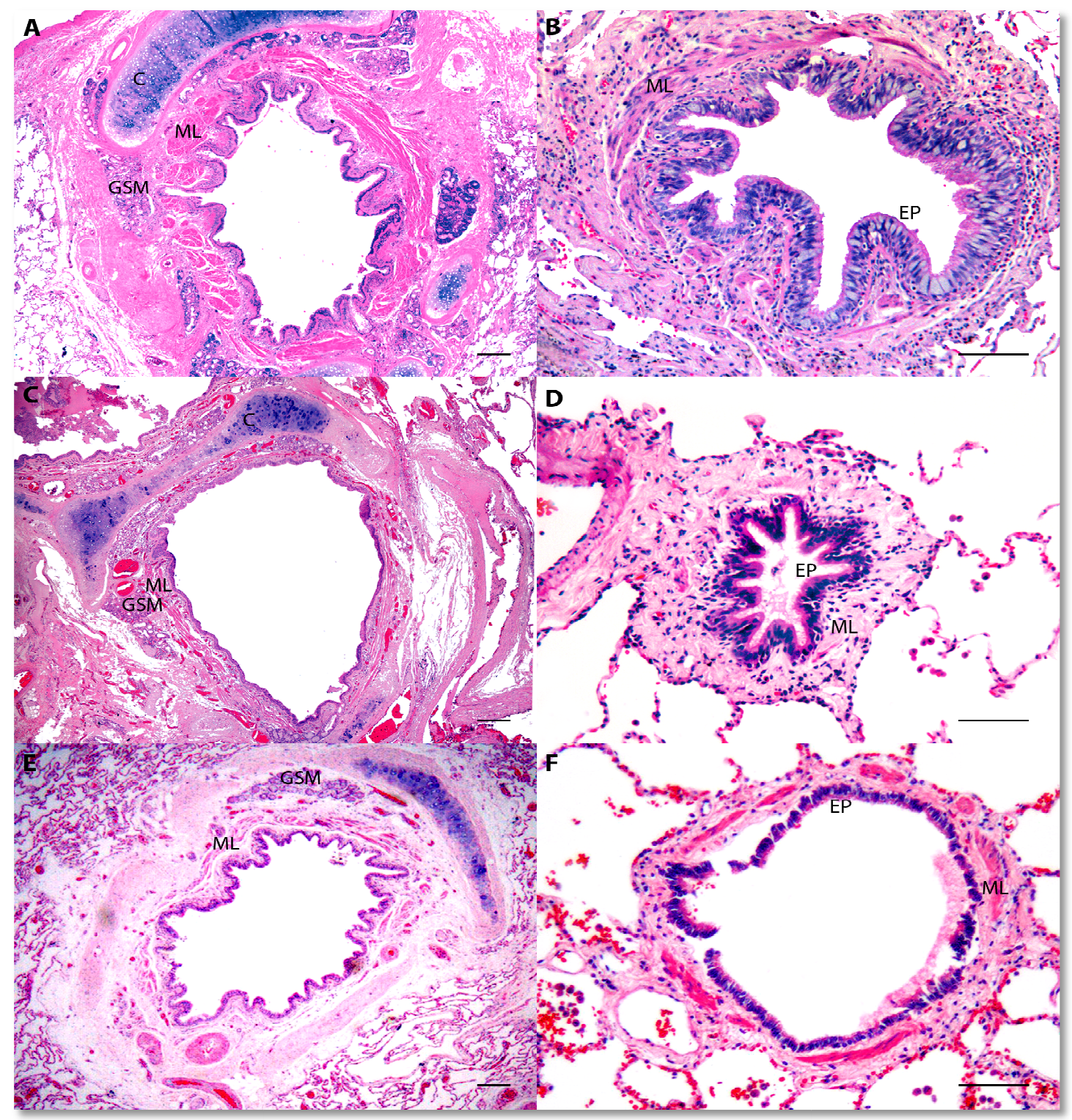

Figura 7. Fotomicrografias das vias aéreas grandes $(A, C$ e E) e das vias aéreas pequenas $(B, D$ e $F)$ de paciente com asma fatal $(A, B), D P O C$ $(C, D)$ e $(E, F)$ de paciente-controle. Observe a proeminente camada de músculo na via aérea (ML) na via aérea dos pacientes asmáticos. Cartilagem (C), músculo liso (ML). Glândula submucosa (GSM), epitélio (EP). Coloração H\&E. A barra de escala em A, C e E corresponde a $250 \mu \mathrm{m}$ e em B, D e F corresponde a $100 \mu \mathrm{m}$. 
Tabela 1. Características clínicas dos pacientes com asma fatal e DPOC

\begin{tabular}{|c|c|c|c|}
\hline & $\begin{array}{l}A F A \\
(n=12)\end{array}$ & $\begin{array}{l}\text { AFI } \\
(n=15)\end{array}$ & $\begin{array}{l}D P O C \\
(n=14)\end{array}$ \\
\hline Indivíduos (M/F) & $2 / 10$ & $4 / 11$ & $8 / 6$ \\
\hline Idade (anos) & $32 \pm 3^{*}$ & $65 \pm 1$ & $71 \pm 1$ \\
\hline Duração da doença (anos) & $23 \pm 4$ & $28 \pm 5$ & NA \\
\hline $\begin{array}{l}\text { Idade de início da } \text { asma } \\
\text { (anos) }\end{array}$ & $8 \pm 2$ & $33 \pm 5^{\dagger}$ & NA \\
\hline Início precoce/tardio asma & $7 / 5$ & $1 / 11$ (3 NA) & - \\
\hline Corticóide sistêmico & $16,7 \%$ & $40 \%$ & $64,3 \%^{\ddagger}$ \\
\hline Corticosteroide Inalatório & $8,3 \%^{\S}$ & $13,3 \% \S$ & $100 \%$ \\
\hline$\beta$-agonista de longa duração & 0 & $13,3 \%$ & $100 \%$ \\
\hline Metilxantinas & $41,7 \%$ & $53,3 \%$ & \\
\hline$\beta$-agonista de curta duração & $92 \%$ & $100 \%$ & $100 \%$ \\
\hline $\begin{array}{l}\text { Admissão Hospitalar Prévia } \\
(\%)\end{array}$ & $33 \%$ & $53,3 \%$ & ND \\
\hline Admissão Prévia em UTI & $16,7 \%$ & $20 \%$ & ND \\
\hline Seguimento Médico(\%) & $33 \%{ }^{\S}$ & $40 \% \|$ & $100 \%$ \\
\hline $\mathrm{VEF}_{1} \%$ pred & ND & ND & $32,31 \pm 3,81$ \\
\hline $\mathrm{VEF}_{1}(\mathrm{~L})$ & ND & ND & $0,81 \pm 0,09$ \\
\hline $\mathrm{VEF}_{1} / \mathrm{CVF}$ & ND & ND & $40 \pm 2,31$ \\
\hline CVF \% pred & ND & ND & $54,69 \pm 4,73$ \\
\hline Tabagismo (maços/ano) & 0 & 0 & $60 \pm 3,4$ \\
\hline Escala de Enfisema** & NA & NA & $41,5 \pm 8,2$ \\
\hline DLCo \% & NA & NA & $42,17 \pm 8,83$ \\
\hline
\end{tabular}


Dados expressos como média \pm erro padrão

\section{Abreviações:}

UTI, Unidade de terapia intensiva

ND, não disponível

NA, não aplicável

AFA, Asma Fatal em pacientes adultos

AFI, Asma Fatal em pacientes idosos e pré-idosos

DPOC, Doença Pulmonar Obstrutiva Crônica

$F_{E V}$, Volume Expiratório Forçado no Primeiro Segundo

CVF, Capacidade Vital Forçada

DLco, Capacidade de Difusão do Monóxido de Carbono

${ }^{*} \mathrm{p}<0,0001$ em relação a AFI e DPOC

${ }^{\dagger} p=0,001$ em relação a $A F A$

${ }^{\ddagger} \mathrm{p}=0,02$ em relação a AFA

$\S_{\mathrm{p}<0,0001 \text { em relação DPOC }}$

$\|_{p=0,001 \text { em relação a DPOC }}$

** Escala de enfisema foi determinada usando as referências 5 e 25 .

\subsection{Morfometria}

No total, foram analisadas 255 vias aéreas, sendo 26 vias aéreas grandes e 16 pequenas no grupo AFA, 34 vias aéreas grandes e 22 vias aéreas pequenas no grupo AFI, 43 vias aéreas grandes e 26 vias aéreas 
pequenas no grupo DPOC, 26 vias aéreas grandes e 18 pequenas no grupo CTRLA e 26 vias aéreas grandes e 18 vias aéreas pequenas no grupo CTRLI. Com relação as medidas da espessura da MB, foram analisadas 59 vias aéreas grandes, sendo 12 no grupo AFA, 15 no grupo AFI, 13 no grupo DPOC, 10 no grupo CTRLA e 9 no grupo CTRLI.

Os resultados apresentados abaixo, podem ser visualizados em forma de tabela no anexo $B$.

\subsubsection{Espessura da Membrana Basal}

Foram realizadas as medidas do perímetro da MB das grandes vias aéreas em 27 (12 AFA e $15 \mathrm{AFI}$ ) nos pacientes com asma, 13 pacientes com DPOC e 19 casos do grupo-controle. Somente um paciente com DPOC não teve vias aéreas grandes disponíveis para análise.

A média erro padrão do perímetro das grandes vias aéreas foi $8770 \mu \mathrm{m} \pm 582 \mu \mathrm{m}$ no grupo AFA, $8913 \mu \mathrm{m} \pm 1019 \mu \mathrm{m}$ na AFI $e$ $11502 \mu \mathrm{m} \pm 800 \mu \mathrm{m}$ na DPOC, $9781 \mu \mathrm{m} \pm 871 \mu \mathrm{m}$ no CTRLA e $10891 \mu \mathrm{m} \pm 1566 \mu \mathrm{m}$ na CTRLI $(p=0,18)$.

A média do comprimento medido da MB das grandes vias aéreas analisada por grupo foi $4,65 \mu \mathrm{m} \pm 90 \mu \mathrm{m}$ na AFA, 4,42 $\mu \mathrm{m} \pm 99 \mu \mathrm{m}$ na AFI, 
$5,06 \mu \mathrm{m} \pm 724 \mu \mathrm{m}$ na DPOC, $3,75 \mu \mathrm{m} \pm 179 \mu \mathrm{m}$ no CTRLA e $3,92 \mu \mathrm{m} \pm 116$ $\mu \mathrm{m}$ na $\mathrm{AFI}(\mathrm{p}=0,11)$.

Não houve diferença estatística na espessura da MB entre os controles $(p=0,96)$. Os pacientes do grupo AFA apresentaram a MB mais espessa que o grupo CTRLA $(p=0,02)$. Não apresentaram diferença estatística na espessura da MB quando comparamos o grupo AFI $(p=0,56)$ e DPOC $(p=1,00)$ com o grupo CTRLI (Gráfico1).

Gráfico 1. Espessura da membrana basal MB $(\mu \mathrm{m})$ das vias aéreas grandes, nos adultos com asma fatal e no grupo controles adultos. Os dados foram expressos em médiaterro padrão.

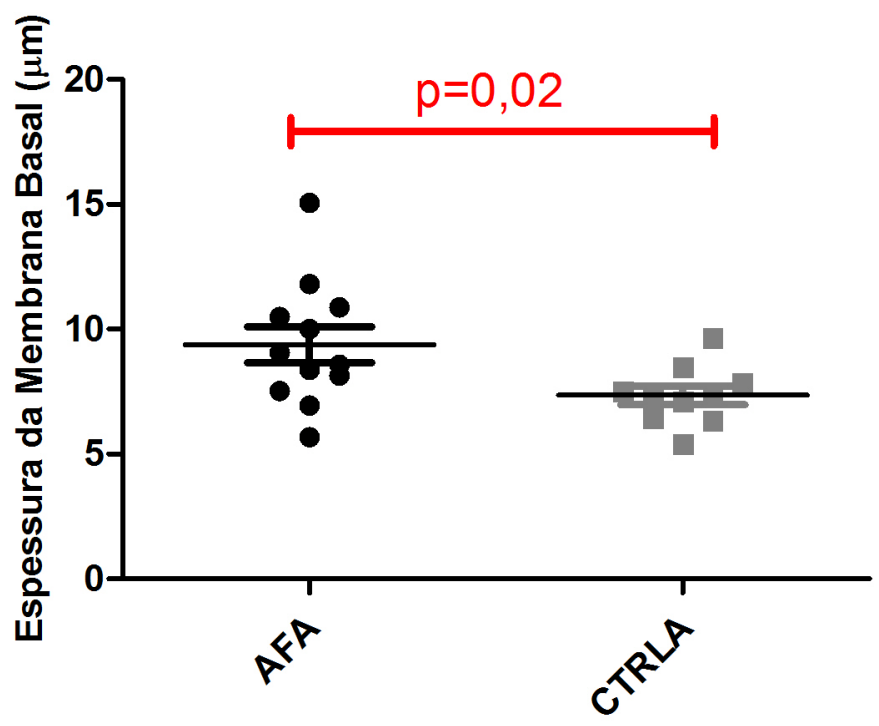


A espessura da MB foi significantemente maior no grupo AFA quando comparado ao DPOC $(p=0,002)$. O grupo AFI teve a espessura média da MB com valores intermedianos nos grupos AFA e o DPOC, não havendo diferença entre eles ( $p>0,3)$ (Figura 8, Gráfico 2).

Gráfico 2. Espessura da membrana basal $(\mu \mathrm{m})$ nos adultos com asma fatal, idosos e pré-idosos com asma fatal e nos pacientes com doença pulmonar obstrutiva grave. Os dados foram expressos em média \pm erro padrão.

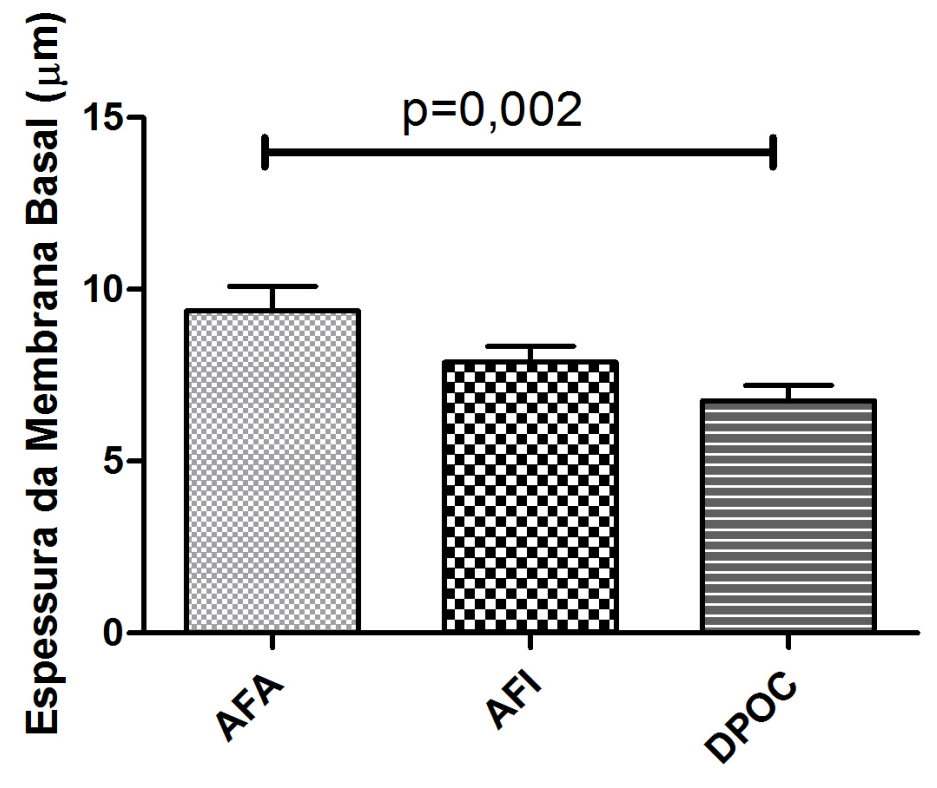




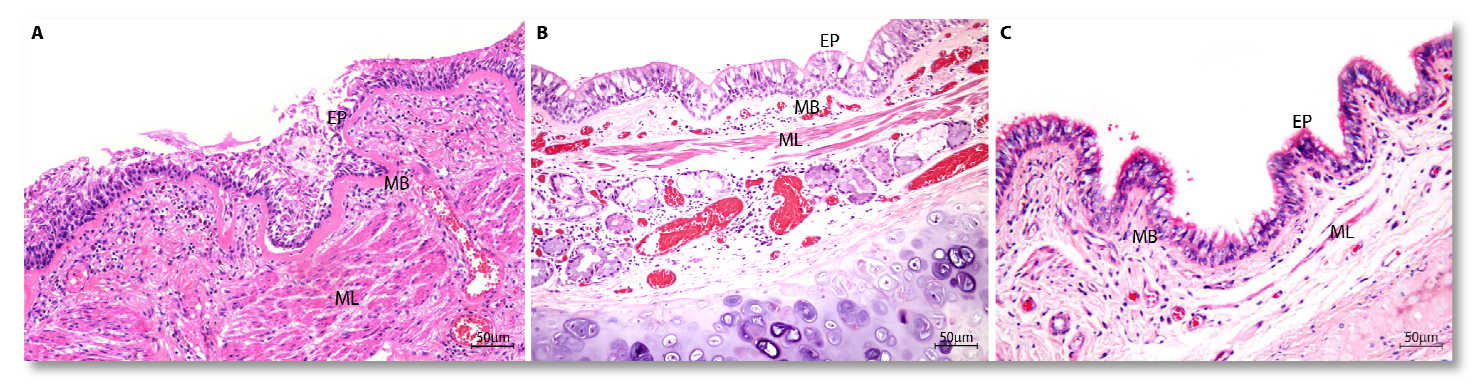

Figura 8. Secção longitudinal das grandes vias aéreas de pacientes asmáticos (A), DPOC (B) e pacientes-controle (C). A membrana basal (MB) em $A$ é mais espessa que em $B$ e $C$ e tem um aspecto hialino e eosinofílico. Observe a espessura do músculo liso em A. Glândula submucosa (GSM), cartilagem (C). H\&E. A barra de escala utilizada foi de $50 \mu \mathrm{m}$.

\subsubsection{Dimensões das vias aéreas}

As dimensões das vias aéreas foram medidas em 21 pacientes (9 AFA e $12 \mathrm{AFI}$ ) com asma, 14 pacientes com DPOC e 19 controles. Seis pacientes foram excluídos das análises das dimensões das vias aéreas porque não houve material para a coloração de Movat's. 


\subsubsection{Controles Adultos versus Controles Idosos e Pré-idosos}

Não houve diferença estatística nas dimensões das vias aéreas grandes e pequenas entre os pacientes controles (CTRLA vs CTRLI), exceto para a área de tecido glândular (GSM), a qual foi maior nos controles idosos $(p=0,036)$ (Gráfico 3). Não houve diferença de gênero em relação à estrutura das vias aéreas em ambas pequenas e grandes vias aéreas. Houve uma correlação positiva entre a área de GSM e a idade $(r=0,63, p=0,005)$ nas grandes vias aéreas. Nenhuma correlação com os parâmetros clínicos foi encontrada nas pequenas vias aéreas. 
Gráfico 3. Área de glândulas submucosas nas grandes vias aéreas nos grupos controles em pacientes adultos e controles em pacientes idosos e pré-idosos. As áreas foram normalizadas pelo perímetro da membrana basal e os dados foram expressos em mediana/IQR.

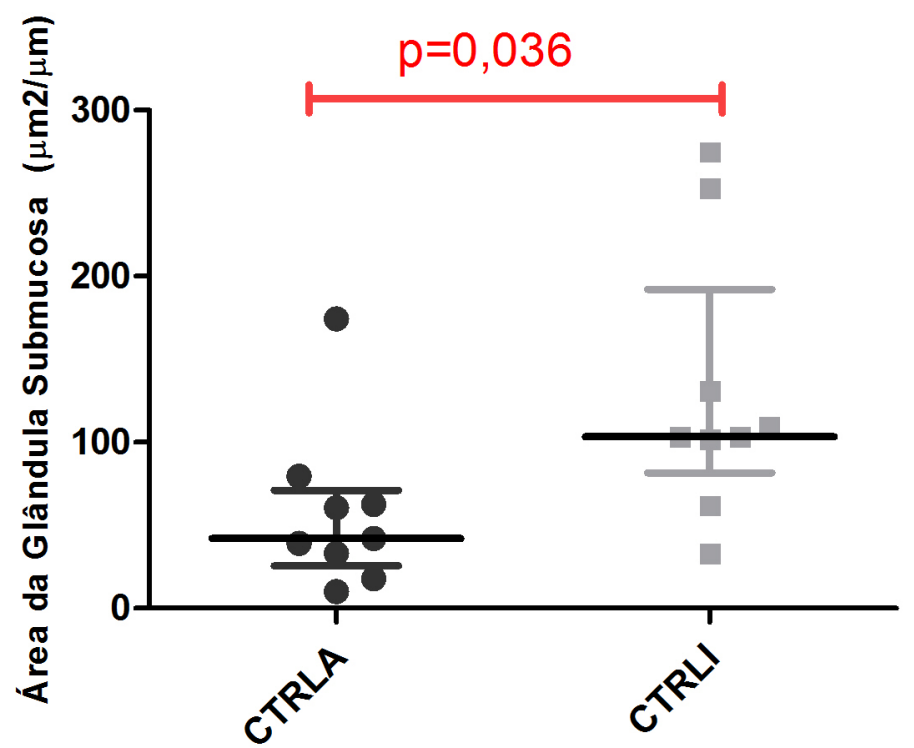

4.3 Controles versus Asma Fatal e Controles versus DPOC, comparados de acordo com a idade

4.3.1 Grupo controle em pacientes adultos versus Grupo asma fatal em pacientes adultos 
Quando analisamos os grupos de acordo com a idade, as vias aéreas grandes do grupo AFA apresentaram a $C I(p=0,01)$, o $M L(p<0,001)$ e a CE $(p<0,001)$ mais espessos que a $\mathrm{Cl}$, o $\mathrm{ML}$ e a CE dos CTRLA (Gráfico 4). As vias aéreas pequenas apresentaram a camada de $M L(p=0,02)$ mais espessa que o CTRLA, não havendo nenhuma diferença estatística entre as outras estruturas (Gráfico 5).

Gráfico 4. Dimensões das grandes vias aéreas dos grupos asma fatal em pacientes adultos e do grupo controles adultos. As áreas foram normalizadas pelo perímetro da membrana basal (MB) e expressos em mediana/IQR. Camada interna $(\mathrm{CI})$, músculo liso $(\mathrm{ML})$ e camada externa (CE).

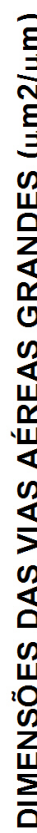

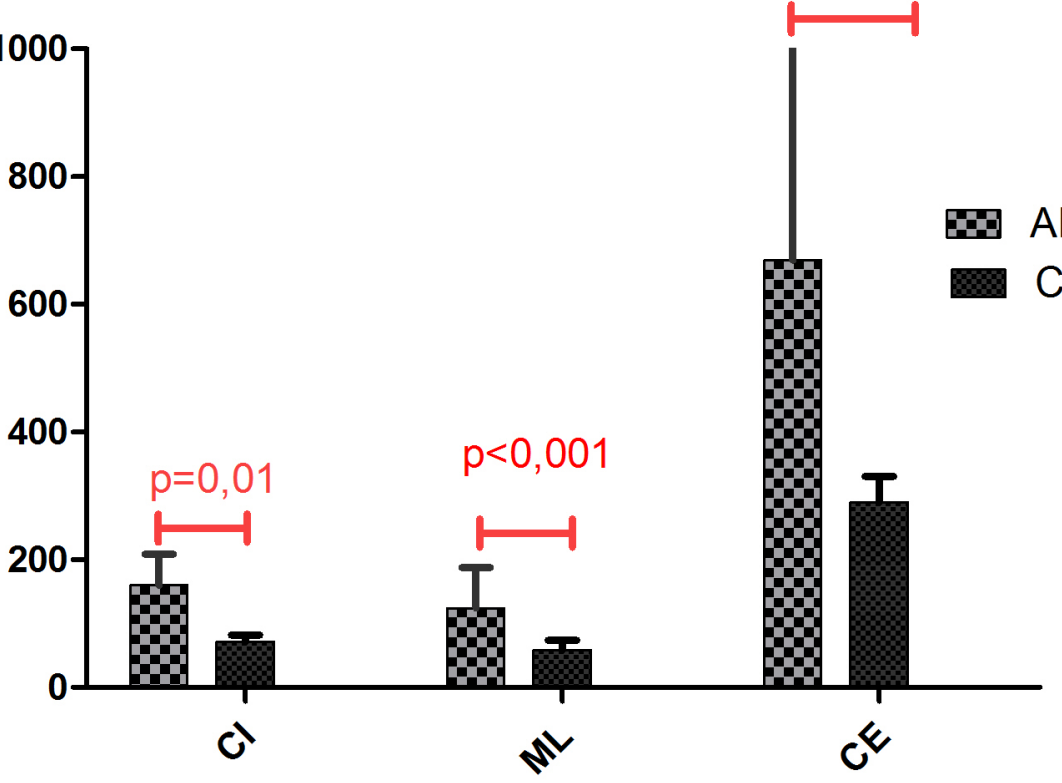


Gráfico 5. Dimensões das pequenas vias aéreas dos grupos asma fatal em pacientes adultos e do grupo controles adultos. As áreas foram normalizadas pelo perímetro da membrana basal (MB) e expressos em mediana/IQR.

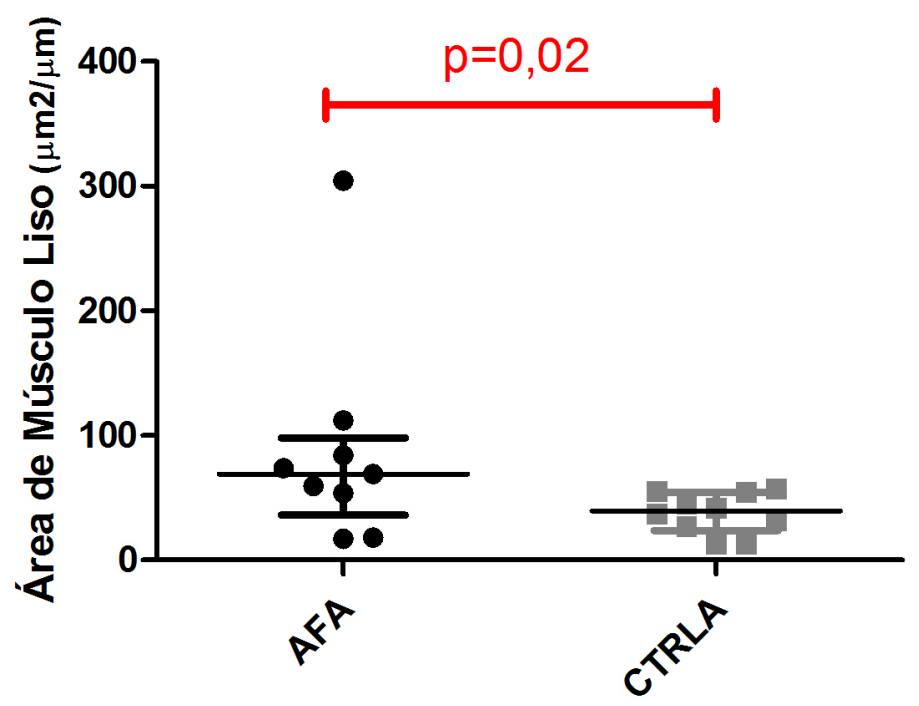

4.3.2 Grupo controle em pacientes idosos e pré-idosos versus grupo asma fatal em pacientes idosos e pré idosos

Ao analisar os grupos de idosos e pré-idosos, as vias aéreas grandes da $\mathrm{AFI}$ apresentaram a $\mathrm{Cl}(\mathrm{p}=0,007)$ mais espessa que os CTRLI, não 
havendo nenhuma diferença estatística nas outras estruturas. Não houve nenhuma diferença estatística em nenhuma estrutura analisada das pequenas vias aéreas (Gráfico 6).

Gráfico 6. Dimensões das grandes vias aéreas dos grupos asma fatal em pacientes idosos e pré-idosos e do grupo controles em pacientes idosos e pré-idosos. As áreas foram normalizadas pelo perímetro da membrana basal (MB), e os dados expressos em mediana/IQR. Camada interna (CI), músculo liso $(\mathrm{ML})$ e camada externa (CE).

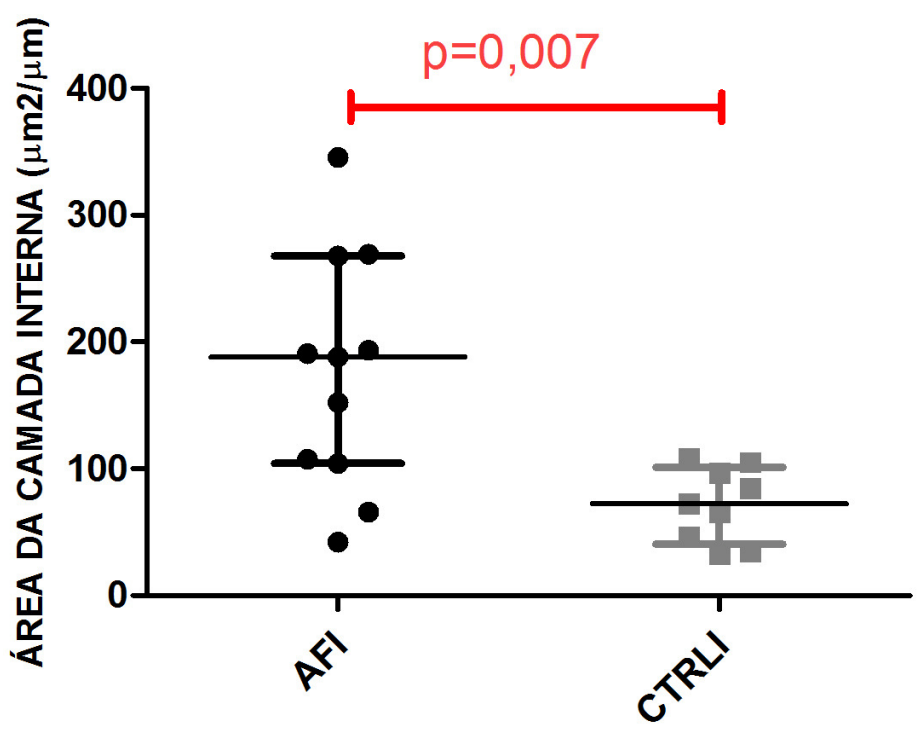


4.3.3 DPOC versus grupo controle em pacientes idosos e préidosos

As vias aéreas grandes do grupo DPOC apresentaram a $\mathrm{Cl}(p=0,01)$ mais espessa que o CTRLI. O grupo CTRLI apresentou a camada de $\mathrm{ML}$ $(p=0,003)$ mais espessa e a área de $\operatorname{GSM}(p=0,01)$ maior que na DPOC. As vias aéreas pequenas do CTRLI apresentaram a camada de $M L(p=0,007)$ mais espessa que na DPOC. Não apresentaram diferença estatística nas outras estruturas analisadas. (Gráficos 7 e 8). 
Gráfico 7. Área da camada interna, área de músculo liso e a área das glândulas submucosas das grandes vias aéreas nos grupos DPOC e controles idosos e pré-idosos. As áreas foram normalizadas pelo perímetro da membrana basal (MB), e os dados expressos em mediana/IQR.
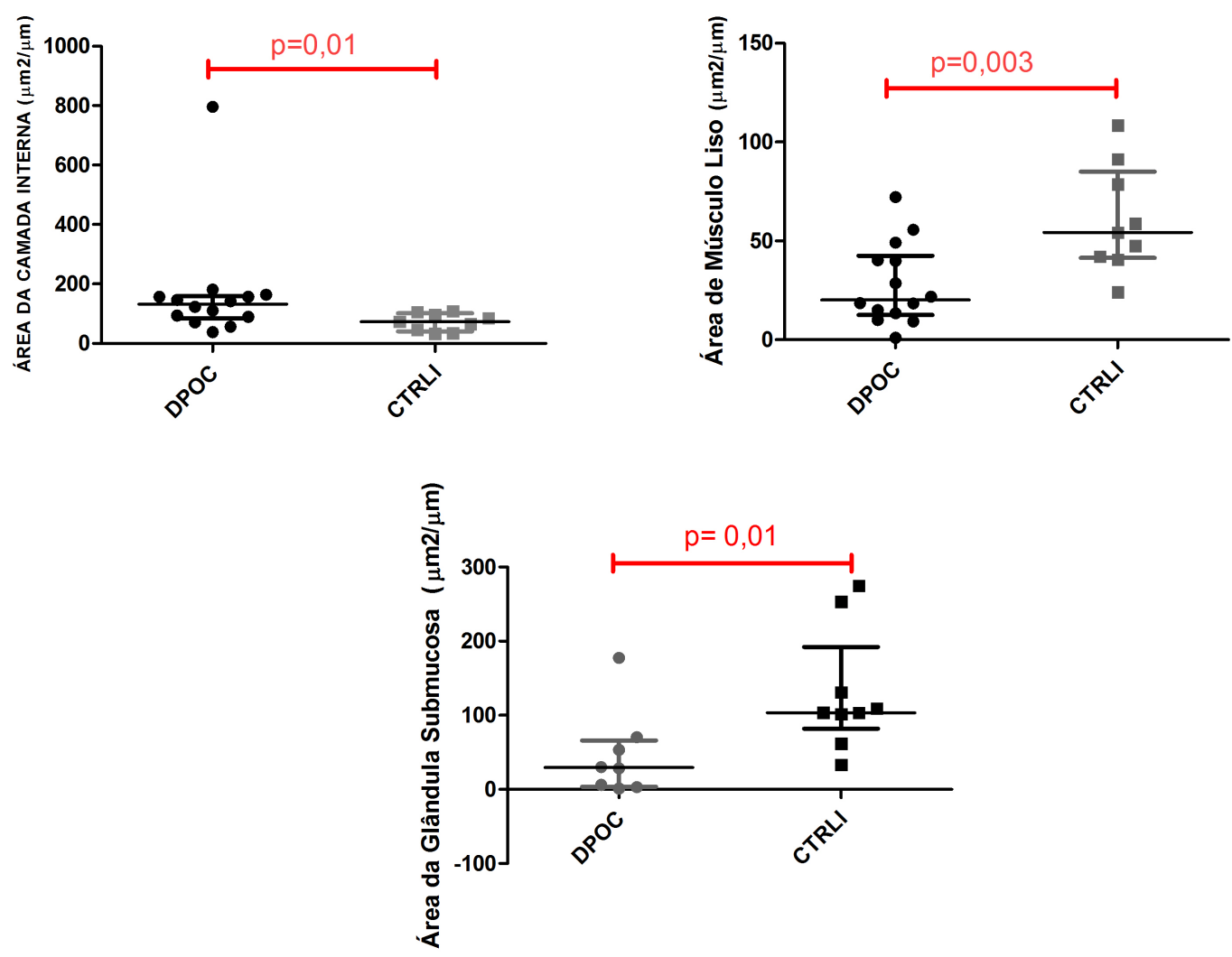
Gráfico 8. Dimensões das pequenas vias aéreas do grupo DPOC e do controles idosos e pré-idosos. As áreas foram normalizadas pelo perímetro da membrana basal (MB), e os dados expressos em mediana/IQR. CTRLI= controles idosos e pré-idosos, DPOC= doença pulmonar obstrutiva crônica.

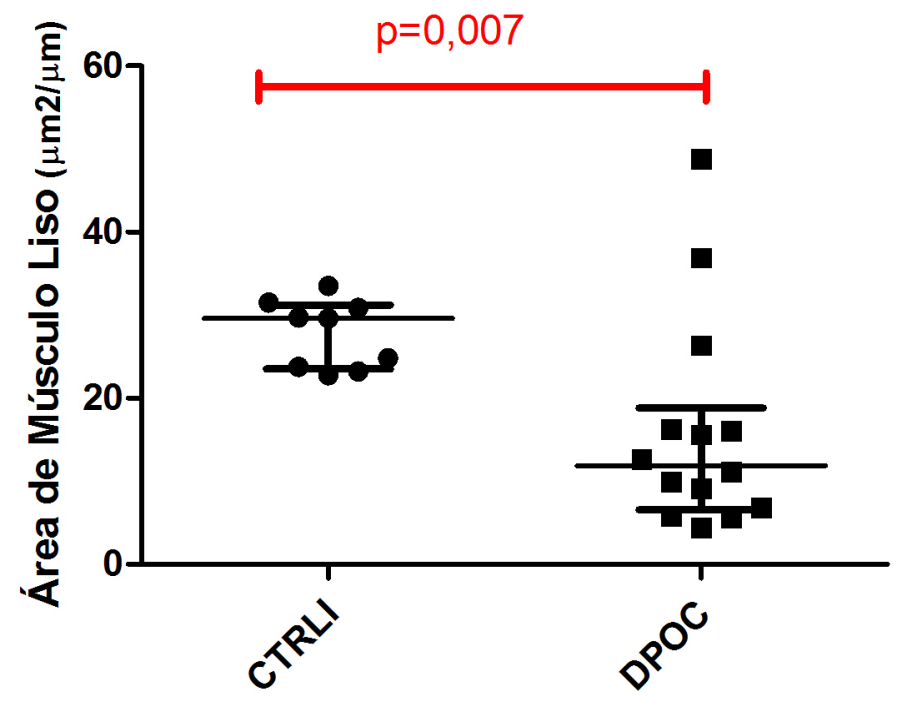

4.4 Grupo asma fatal em pacientes adulto versus grupo asma fatal em pacientes idosos versus DPOC

Quando comparamos os casos de asma fatal agrupados de acordo com a idade, observamos que AFA e AFI apresentaram a camada de $\mathrm{ML}$ e a CE mais espessas nas grandes vias aéreas quando comparadas ao DPOC. Os dados e os valores de $p$ são apresentados nos Gráficos 9 e 10. No subgrupo de 21 pacientes, a espessura da MB nas grandes vias aéreas 
apresentaram resultados semelhantes ao um maior grupo de pacientes $(n=27)$. Os pacientes do grupo AFA apresentaram a espessura da MB maior que o grupo de pacientes DPOC $(p=0,009)$ com valores intermediários no grupo AFI (AFI vs. DPOC, $\mathrm{p}=0,24 ; \mathrm{AFA}$ vs. $\mathrm{AFI}, \mathrm{p}=0,25)$.

Gráfico 9. Área do músculo liso e a área da camada externa das grandes vias aéreas nos grupos AFA, AFI e DPOC. As áreas foram normalizadas pelo perímetro de $\mathrm{MB}\left(\mu \mathrm{m}^{2} / \mu \mathrm{m}\right)$. Os dados são apresentados em mediana/IQR. Músculo liso (ML) e camada externa (CE).

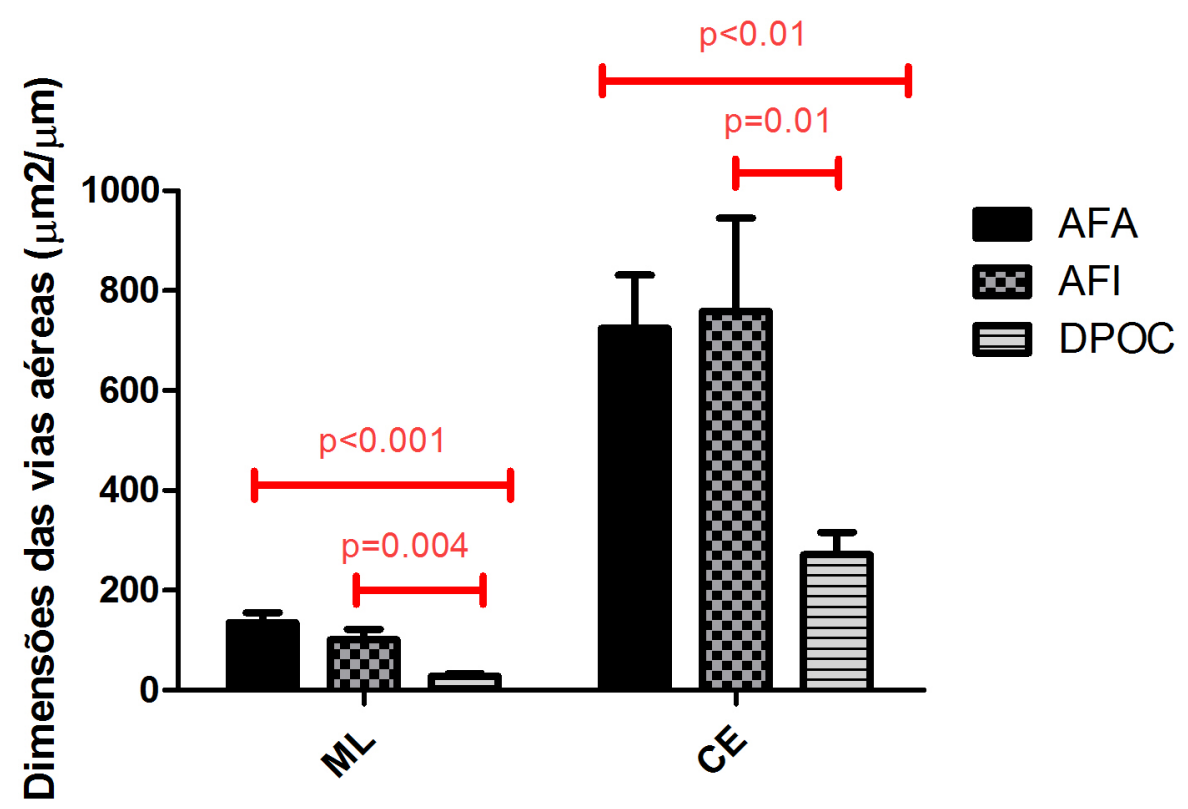


Gráfico 10. Espessura da membrana basal das grandes vias aéreas no subgrupo de 21 pacientes, entre a asma fatal e a DPOC. Apresentando valores intermediários nos grupos AFI e DPOC (AFI vs. DPOC, $p=0,24 ; A F A$ vs. AFI, $\mathrm{p}=0,25)$.

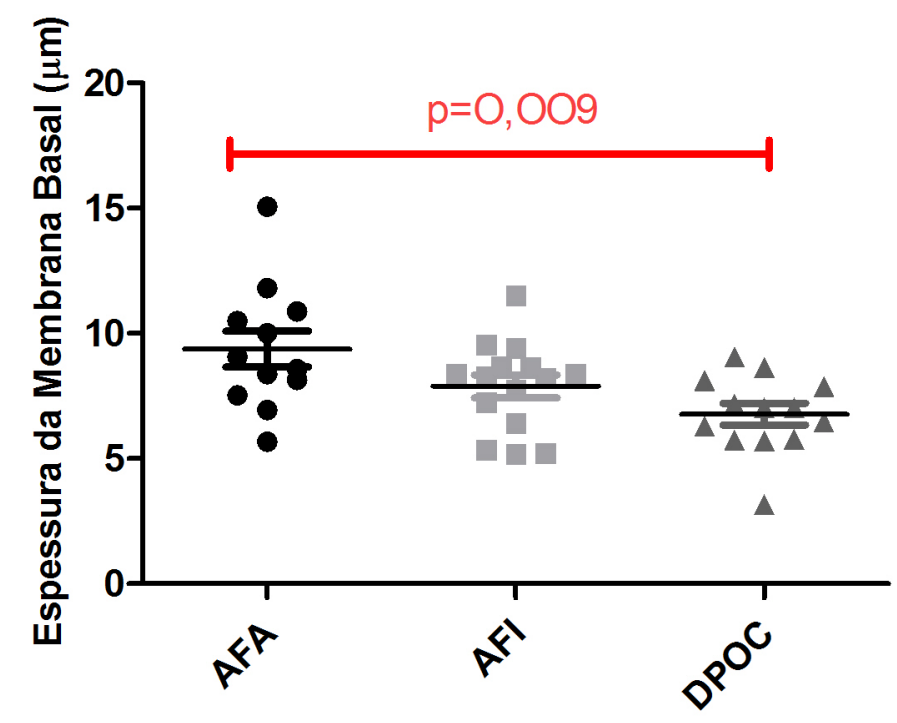

Quando comparamos os casos de asma agrupados de acordo com a idade de morte, observamos que AFI e DPOC apresentaram as dimensões dos compartimentos das pequenas vias aéreas semelhantes, com diferenças observadas somente entre AFA e DPOC na camada de ML $(p=0,004)$ e na CE $(p=0,01)$ das pequenas vias aéreas. Os dados e os valores de $p$ são apresentados no Gráfico 11. 
Gráfico 11. Área do músculo liso e a área da camada externa das pequenas vias aéreas nos grupos AFA, AFI e DPOC. As áreas foram normalizadas pelo perímetro de $\mathrm{MB}\left(\mu \mathrm{m}^{2} / \mu \mathrm{m}\right)$. Os dados são apresentados em mediana/IQR. Músculo liso (ML) e camada externa (CE).

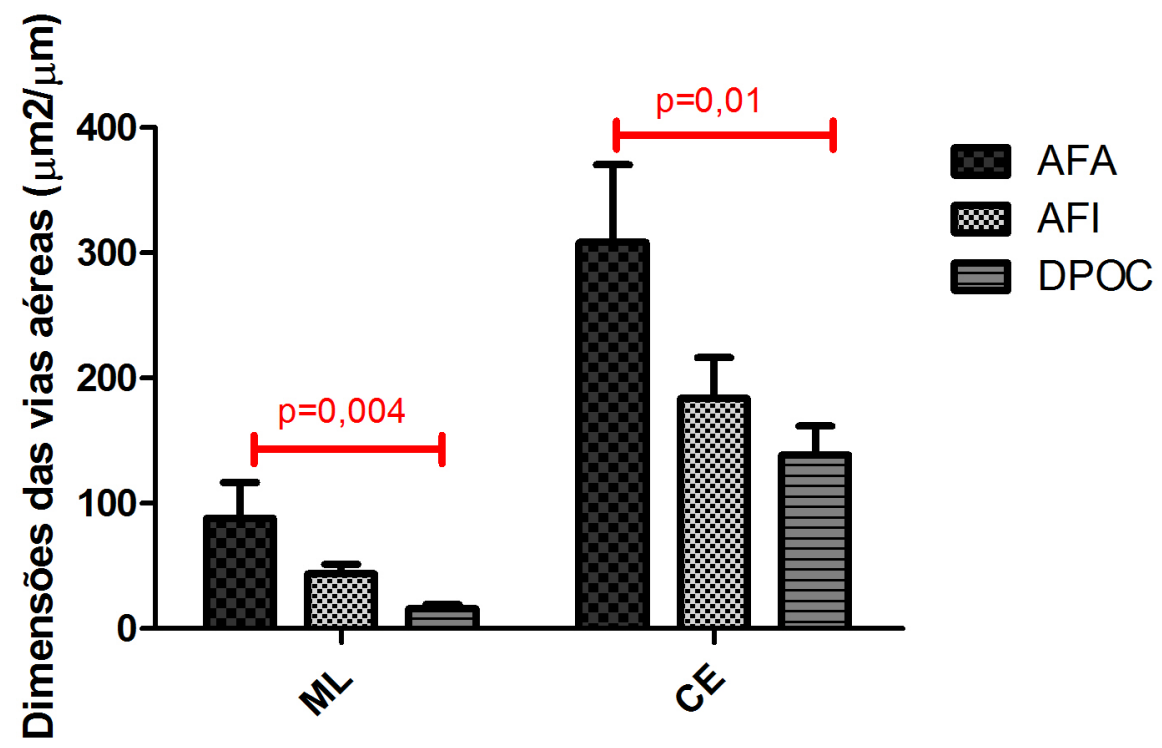

4.5 A influência do uso de corticosteroides e da idade de início da asma

Os asmáticos que haviam feito uso regular de corticosteroides não apresentaram diferença significante na espessura da MB e nas dimensões das estruturas das vias aéreas em relação aos que não usaram. Houve uma tendência menor a área de ML nas VAG dos pacientes asmáticos que 
usaram esteroides regularmente (dimensão do ML no pacientes que usaram corticosteroides: $87,1 \mu \mathrm{m}^{2} / \mu \mathrm{m}$; dos que não usaram corticosteroides: 129,47 $\left.\mu \mathrm{m}^{2} / \mu \mathrm{m} ; \mathrm{p}=0,06\right)$.

Os pacientes asmáticos foram categorizados de acordo com a idade de início da asma. Os pacientes que tiveram asma de início precoce $(n=7)$, apresentaram a área de ML maior nas grandes vias aéreas (início precoce= $169,05 \pm 27,46 \mu \mathrm{m}^{2} / \mu \mathrm{m}$, início tardio $=92,62 \pm 12,03 \mu \mathrm{m}^{2} / \mu \mathrm{m}, \mathrm{p}=0.009$ ) e a área da CE maior nas pequenas vias aéreas (início precoce $=357,16 \pm 61,66 \mu \mathrm{m}^{2} / \mu \mathrm{m}$, início tardio=175,96 $\pm 34,52, \mathrm{p}=0,012$ ). 
5 DISCUSSÃO 


\section{DISCUSSÃO}

Em pessoas idosas, a asma não é incomum, porém é frequentemente subdiagnósticada e subtratada. $\mathrm{O}$ envelhecimento está associado com problemas únicos que modificam a expressão, o reconhecimento e o tratamento da doença. Muitos pacientes apresentam obstrução irreversível das vias aéreas, devido a um severo remodelamento das vias aéreas, doença pulmonar obstrutiva crônica e bronquiectasia. ${ }^{20} \mathrm{Na}$ asma, em particular, a asma e a DPOC, sobrepõem-se e convergem em pessoas, idosas. Essa simultaneidade, aliada à ausência de métodos precisos de identificação, torna complexo o diagnóstico. Maior atenção às complicações da asma e das doenças obstrutivas das vias aéreas em pessoas idosas é necessário, especialmente para desenvolver sistemas eficazes de tratamento adequado e de diretrizes da prática clínica. ${ }^{21}$

Neste estudo, comparamos as dimensões das vias aéreas de pacientes adultos que vieram a óbito por asma fatal e por DPOC agrupados pela idade do óbito e comparamos com um grupo controle. Nós mostramos que os pacientes idosos e pré-idosos que foram a óbito por asma tem alterações estruturais das vias aéreas, especialmente nas pequenas vias aéreas, que são semelhantes aos pacientes que faleceram por DPOC. Estas similaridades nos parecem estar vinculadas somente ao processo de envelhecimento, uma vez que não detectamos muitas alterações estruturais nas vias aéreas de pacientes idosos e pré-idosos em relação aos pacientes adultos que morreram sem alterações pulmonares (controles). Esses 
achados sugerem que essas diferenças observadas entre os grupos asma fatal em pacientes adultos e DPOC são improváveis que reflitam somente o processo de envelhecimento.

Alguns estudos indicam que a senilidade dos pulmões é caracterizada por alargamento homogêneo dos espaços aéreos, com ou sem fibrose, e sem destruição de suas paredes. Existem poucos estudos patológicos em humanos sobre a influência do envelhecimento na estrutura das vias aéreas. ${ }^{22}$ Bai et al não observaram diferenças nas estruturas das vias aéreas entre dois grupos de adultos (a média da idade do grupo jovem era de 23 anos, já a média da idade do grupo adulto era de 47,8 anos). ${ }^{23}$ Em contraste, Nagai et $\mathrm{al}^{13}$ compararam as estruturas das pequenas vias aéreas de 7 pacientes adultos-jovens (média de idade de 31,7 anos) e 7 mais velhos (média de idade de 60,9 anos) e relataram que os controles mais velhos apresentaram área de músculo menor nas vias aéreas periféricas. Nossos dados dos sujeitos idosos mostram diferenças somente na área das glândulas. Tomados em conjunto, os estudos sugerem que o envelhecimento afeta de forma mais consistente as regiões alveolares do que as estruturas das vias aéreas.

Nosso grupo CTRLA não foi perfeitamente pareado pela idade com o AFA, o que é uma importante limitação do estudo. No entanto, Bai et al não encontrou diferenças nas estruturas das vias aéreas nos pacientes-controles com idade similar aos nossos controles e aos asmáticos adultos. ${ }^{23}$ Quando comparado o grupo AFA com o grupo CTRLA, o grupo AFA tiveram as dimensões das vias aéreas maiores que as dos controles, mas poucas 
diferenças foram encontradas entre o $\mathrm{AFI}$ e seus respectivos controles. Essas nuances podem estar relacionadas à variação do fenótipo da asma em ambas as faixas etárias.

Interessantemente, os pacientes idosos e pré-idosos que morreram de asma e os pacientes com DPOC grave não tiveram evidências de aumento das dimensões das vias aéreas, exceto por um aumento na área de $\mathrm{Cl}$ nas grandes vias aéreas. Além disso, os pacientes com DPOC grave apresentaram a área de MI menor nas VAG e nas VAP. Esses resultados parecem conflitar com o pressuposto de que o DPOC sempre está associado ao espessamento das vias aéreas. Recentes estudos sugerem que os bronquíolos podem ser obliterados e desaparecer nos pacientes com enfisema extenso e DPOC grave. Nossos resultados com os pacientes com DPOC grave certamente dão suporte para esse pressuposto. ${ }^{24}$ Nagai e colegas $^{13}$ encontraram uma relação negativa entre a área de $M L$ nas grandes vias aéreas e a extensão do enfisema. Além disso, a expressão dos genes relacionados à deposição da matriz extracelular e aos fatores de crescimento diminui com a progressão do volume expiratório forçado no primeiro segundo $\left(\mathrm{VEF}_{1}\right)$, como apresentado por Hogg et al. ${ }^{24}$

A função pulmonar diminui com a idade, e esta redução é maior em homens do que nas mulheres. As razões para a redução incluem, enrijecimento da parede torácica, redução da função dos músculos respiratórios, aumento do volume residual e perda do recolhimento elástico do pulmão. Como resultado, os asmáticos idosos apresentam pobre resposta ao uso de broncodilatadores e ao uso de corticóides. ${ }^{20}$ 
Não existem estudos que compararam as estruturas das pequenas e grandes vias aéreas na asma fatal e na DPOC grave com idade e severidade das doenças similares. No presente estudo, mostramos que o grupo AFI teve o espessamento da MB intermediário quando comparado ao AFA e ao DPOC grave. O espessamento da lâmina reticular devido à deposição da matriz extracelular é considerado uma característica patognomônica da asma. $^{25}$ Muitos estudos têm mostrado maior espessamento da MB nos asmáticos quando aos pacientes com DPOC, enquanto outros não Liesker e colegas apesar de mostrarem que a espessura da MB entre asma e da DPOC é similar, descreveram que a composição da matriz extracelular é diferente nas duas doenças. ${ }^{26,27}$

Nossos resultados mostram que os pacientes do grupo AFA tiveram MB mais espessa que os pacientes com DPOC, mas uma sobreposição existe no grupo AFI. Na asma, o papel da liberação de eosinófilos mediada pelo TGF- $\beta$ pode contribuir para deposição da matriz extracelular ao nível da $M B .^{28}$ Além disso, pacientes com asma de início tardio e sem eosinofilia pulmonar também não apresentaram aumento na espessura da $M B .{ }^{14,15}$ É possível que as diferenças de eosinofilia possam explicar a MB menos espessa observada no grupo DPOC.

Não encontramos diferenças nas $\mathrm{Cl}$ das grandes e pequenas vias aéreas entre os pacientes com asma fatal e os que têm DPOC. Essas similaridades podem ser devido um nível semelhante de inflamação, deposição de matriz extracelular, aumento da vascularidade ou pela combinação desses parâmetros. Em recentes estudos de Bourdin et $\mathrm{al}^{29}$, 
estes relataram que patologistas não especialistas são incapazes de diferenciar a asma leve e moderada da DPOC quando analisadas por biópsia endobrônquica, um procedimento que predominantemente analisa amostras de $\mathrm{MB}$ e $\mathrm{Cl}$ nas grandes via aéreas.

O aumento da massa do ML é uma característica estrutural importante da asma ${ }^{7,11,30}$ e o maior determinante da hiper-responsividade da via aérea na asma e na DPOC. ${ }^{6}$ Estudos anteriores têm demonstrado aumento da massa do ML nos pacientes com DPOC leve quando comparados com controles, mas não com pacientes asmáticos. ${ }^{11}$ Nossos dados mostram que a quantidade de massa de ML nas grandes vias aéreas é uma característica que distingue a asma da DPOC independentemente da idade.

Nós observamos que é improvável que a duração da doença esteja relacionado às similaridades entre os asmáticos idosos e pré-idosos e os pacientes com DPOC, porque ambos os grupos de asma fatal tiveram similar tempo de duração da doença. Por outro lado, existem diferenças relacionadas à idade de início da asma, com a maioria de asmáticos idosos tendo início tardio da doença. A idade de início da asma parece estar relacionada com diferentes fenótipos clínicos. Os asmáticos com início tardio têm menos atopia, maior limitação do fluxo aéreo respiratório e padrões distintos de inflamação mediada por neutrófilos em biópsias brônquicas. ${ }^{14,15}$ Nossos dados sugerem que o fenótipo da asma com início precoce está relacionado com mais proeminentes alterações estruturais em ambas as 
pequenas e grandes vias aéreas na asma fatal do que em asmáticos com início tardio da doença.

Este estudo tem importantes limitações. Nossa população de asma fatal é caracterizada pelo uso limitado de corticosteroides inalatórios e pela falta de cuidados médicos regulares, todos fatores de risco para complicações da asma e morte. ${ }^{31}$ Não houve estudos da função pulmonar na maioria dos pacientes. Apesar disso, os dados disponíveis sugerem que uma grande proporção dos pacientes tenha sinais de asma severa pobremente controlada.

Um importante fator que confunde este estudo é o fato de todos os pacientes com DPOC terem usado corticosteroide inalatório, e enquanto um pequeno número de asmáticos usavam esta droga regularmente. Existem poucos dados sobre os efeitos dos corticosteroides nas estruturas das vias aéreas na asma e na DPOC. Evidências sugerem que os corticosteróides não podem reverter a deposição de colágeno brônquico na asma ${ }^{6}$. Neste estudo, quando comparamos o uso de corticosteroides entre os asmáticos, não conseguimos encontrar diferenças significantes nas estruturas das vias aéreas. Porém, não se pode excluir que algumas das diferenças estruturais encontradas entre os grupos possam ter sido influenciadas pelo uso mais regular dos corticosteroides nos pacientes com DPOC.

Em conclusão, os pacientes do grupo AFA tiveram a espessura da MB maior, maior área de músculo e parede externa quando comparados aos pacientes com DPOC grave. Os pacientes AFI, apesar de apresentarem a 
duração da asma similar ao $\mathrm{AFA}$, têm alterações como à espessura da $\mathrm{MB}$ nas grandes vias aéreas e anormalidades estruturais as vias aéreas como os semelhantes aos pacientes com DPOC grave. Esses resultados não parecem refletir tão somente o envelhecimento e podem ser influenciados pela idade de início da asma. A asma no idoso é uma doença grave, mas frequentemente subdiagnosticada e subtratada, com relativas altas taxas de mortalidade. ${ }^{3}$ Acreditamos que é essencial melhor entender a patogênese da asma e sua relação com a DPOC no subgrupo de indivíduos idosos. ${ }^{21}$ 
6 CONCLUSÕES 


\section{CONCLUSÕES}

- Não houve diferença nas dimensões das vias aéreas entre os pacientes dos grupos controles, exceto na área de glândulas submucosas que foi maior no grupo controle de idosos e pré-idosos.

- Os pacientes adultos que foram a óbito por asma apresentaram maiores dimensões das grandes vias aéreas (a área da camada interna e a área de músculo liso) em relação ao grupo de pacientes controles adultos. Nas vias aéreas pequenas apresentaram somente a camada de músculo liso maior que os pacientes do grupo controle adultos.

- Poucas diferenças foram observadas nas dimensões das vias aéreas entre os pacientes idosos e pré-idosos que foram a óbito por asma e o grupo controle de pacientes idosos e pré-idosos. A única diferença encontrada foi uma maior dimensão da camada interna das grandes vias aéreas dos pacientes idosos que vieram a óbito por asma.

- Nos pacientes com DPOC, as dimensões da camada interna, de músculo liso e de glândulas submucosas nas grandes vias aéreas foram menores quando comparadas ao grupo controle de pacientes idosos e pré-idosos. Nas pequenas vias aéreas, as dimensões da camada muscular lisa foram menores nos pacientes com DPOC em relação ao grupo controle de pacientes idosos e pré-idosos.

- Os pacientes adultos que foram a óbito por asma apresentaram a espessura da membrana basal epitelial maior em relação aos pacientes com DPOC grave, sendo que no grupo de pacientes idosos e pré-idosos foram observados valores intermediários entre os dois 
grupos. Não houve diferença na espessura da membrana basal entre os pacientes dos grupos controles.

- Os pacientes com asma fatal de ambos os grupos apresentaram maiores dimensões da camada de músculo liso e da camada externa nas grandes vias aéreas em relação aos pacientes com DPOC. Nas pequenas vias aéreas, os pacientes idosos e pré-idosos que morreram de asma e os pacientes com DPOC apresentaram as dimensões das vias aéreas semelhantes. Os pacientes adultos que morreram de asma apresentaram maiores dimensões da camada de músculo liso e da camada externa que os pacientes com DPOC.

- Os pacientes que fizeram uso regular de corticosteróides não apresentaram diferença significante na espessura da MB e nas dimensões das estruturas das vias aéreas em relação aos que não usaram.

- Os pacientes com asma fatal de início precoce apresentaram maiores dimensões da camada de músculo liso nas grandes vias aéreas e da camada externa nas pequenas vias aéreas.

- Em suma, pacientes mais velhos com doenças pulmonares obstrutivas (asma e DPOC) mostram semelhanças nas dimensões estruturais das vias aéreas, especialmente das pequenas $v$ ias aéreas. 
8 ANEXOS 


\section{Anexo A}

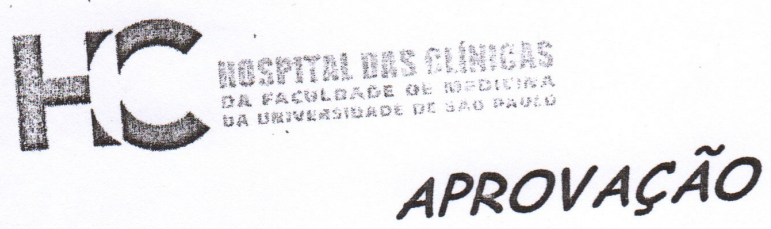

A Comissão de Ética para Análise de Projetos de Pesquisa - CAPPesq da Diretoria Clínica do Hospital das Clínicas e da Faculdade de Medicina da Universidade de São Paulo, em sessão de 13.09.06, APROVOU o Protocolo de Pesquisa $n^{\circ} 844 / 06$, intitulado: "Similaridades e diferenças morfológicas entre asma fatal e a doença pulmonar obstrutiva grave" apresentado pelo Departamento de PATOLOGIA.

Cabe ao pesquisador elaborar $e$ apresentar à CAPPesq, os relatórios parciais e final sobre a pesquisa (Resolução do Conselho Nacional de Saúde $n^{\circ} 196$, de 10.10.1996, inciso IX. 2, letra " $c$ ")

Pesquisador(a) Responsável: $\operatorname{Dr}(a)$ : Thais Mauad Pesquisador (a) Executante: Sr(a): Aletéa Senhorini CAPPesq, 13 de Setembro de 2006.

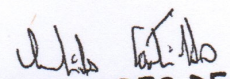

PROF. DR. EUCLIDES AYRES DE CASTILHO Presidente da Comissão de Ética para Análise de Projetos de Pesquisa 


\section{Anexo B}

Anexo A. Tabela das dimensões das vias aéreas na asma fatal, DPOC grave e nos controles

\begin{tabular}{|c|c|c|c|c|c|c|c|c|}
\hline & $\overline{A F A}$ & $\overline{C T R L A}$ & $p^{*}$ & $\overline{\mathrm{AFI}}$ & CTRLI & DPOC & $\mathbf{p}^{* *}$ & $p^{* \star *}$ \\
\hline MB & $9,37 \pm 0,71+$ & $7,35 \pm 0,37$ & 0,02 & $7,88 \pm 0,45$ & $7,37 \pm 0,38$ & $6,77 \pm 0,42$ & 0,25 & 0,40 \\
\hline VAG-CI & $159,96 / 108,85$ & $71,50 / 21,91$ & 0,01 & $188,17 / 163,60$ & $72,60 / 60,41$ & $132,34 / 73,95$ & 0,007 & 0,01 \\
\hline VAG-ML & $124,05 / 100,69$ & $58,51 / 28,69$ & $<0,001$ & $100,29 / 95,23$ & $54,36 / 43,60$ & $20,23 / 29,97$ & 0,20 & 0,003 \\
\hline LA-CE & $668,85 / 52,35$ & $290,15 / 126,98$ & 0,001 & $711,09 / 1209,30$ & $181,96 / 187,52$ & $29,41 / 62,31$ & 0,067 & 0,01 \\
\hline GSM & $21,00 / 71,80$ & $42,05 / 45,6++$ & 0,54 & $114,55 / 181,91$ & $103,39 / 110,40$ & $29,41 / 62,31$ & 0,83 & 0,01 \\
\hline VAP-CI & $74,06 / 29,76$ & $60,83 / 43,67$ & 0,40 & $72,76 / 44,59$ & $32,26 / 35,42$ & $56,54 / 56,03$ & 0,058 & 0,06 \\
\hline VAP-ML & $69,28 / 61,95 £$ & $34,42 / 28,72$ & 0,02 & $37,59 / 38,62$ & $29,60 / 7,69$ & $11,87 / 12,26$ & 0,08 & 0,007 \\
\hline VAP-CE & $273,59 / 233,58 €$ & $186,08 / 122,75$ & 0,06 & $157,72 / 207,16$ & $159,70 / 124,36$ & $109,12 / 139,29$ & 1,00 & 0,22 \\
\hline
\end{tabular}

$\mathrm{AF}=$ asma fatal, $\mathrm{DPOC}=$ doença pulmonar obstrutiva crônica, $\mathrm{A}=$ adultos, $\mathrm{I}=$ idosos, $\mathrm{CTRL}=$ controles, $\mathrm{MB}=\mathrm{Membrana} \mathrm{Basal}, \mathrm{VAG}=\mathrm{via}$ aérea grande, $\mathrm{VAP}=$ via aérea pequena, $\mathrm{Cl}=$ área da camada interna, $\mathrm{ML}=$ área do músculo liso, $\mathrm{CE}=$ área da camada externa, $\mathrm{GSM}=$ área da glândula submucosa.

$p^{*}$ AFA vs. CTRLA ; $p^{* *}$ AFI vs. CTRLI ; $p^{* *}$ CTRLI vs. DPOC; + AFA vs. DPOC, $p=0.009 ;++C T R L A$ vs. CTRLI, $p=0.036 ; £ A F A$ vs. DPOC, $p=$ $0.004, ; €$ AFA vs. DPOC, $p=0.01$ 


\section{REFERÊNCIAS}

1. Lopez AD, Shibuya K, Rao C, Mathers CD, Hansell AL, Held LS, et al. Chronic obstructive pulmonary disease: current burden and future projections. Eur Respir J 2006; 27:397-412.

2. Masoli M, Fabian D, Holt S, Beasley R: Global Initiative for Asthma (GINA) Program. The global burden of asthma: executive summary of the GINA Dissemination Committee report. Allergy 2004;59:469-78.

3. Global strategy for asthma management and prevention revised 2009. Available in http://www.ginasthma.com.

4. Global strategy for the diagnosis, management, and prevention of chronic obstructive pulmonary disease 2009. Available in: http://goldcopd.com.

5. Jeffery PK. Remodelling in asthma and chronic obstructive lung Disease. Am J Respir Crit Care Med 2001;164:S28-38.

6. Jeffery PK. Remodeling and Inflammation of bronchi in asthma and Chronic Obstructive Pulmonary Disease. Proc Am Thoracic Soc 2004; 1:17683.

7. Lambert RK, Wiggs BR, Kuwano K, Hogg JC, Pare PD. Functional significance of increased airway smooth muscle in asthma and COPD. J Appl Physiol 1993;74:2771-81. 
8. Mauad T, Bel EH, Sterk PJ. Asthma therapy and airway remodeling. $\mathrm{J}$ Allergy Clin Immunol 2007;120:997-1009.

9. Aoshiba K, Nagai A. Differences in airway remodeling between asthma and chronic obstructive pulmonary disease. Clin Rev Allergy Immunol 2004; 27:35-43.

10. Sutherland ER, Martin RJ. Airway inflammation in chronic obstructive pulmonary disease: comparisons with asthma. J Allergy Clin Immunol 2003; 112:819-27.

11. Kuwano K, Bosken CH, Pare PD, Bai TR, Wiggs BR, Hogg JC. Small airways dimensions in asthma and in chronic obstructive pulmonary disease. Am Rev Respir Dis 1993;148:1220-5.

12. Vignola AM, Scichilone N, Bousquet J, Bonsignore G, Bellia V. Aging and asthma. pathophysiological mechanisms. Allergy 2003;58:165-75.

13. Nagai A, West WW, Paul JL, Thurlbeck WM: The National Institutes of Health Intermittent Positive-Pressure Breathing trial: pathology studies. I. Interrelationship between morphologic lesions. Am Rev Respir Dis 1985;132:937-45.

14. Miranda C, Busacker A, Balzar S, Trudeau J, Wenzel SE. Distinguishing severe asthma phenotypes: role of age at onset and eosinophilic inflammation. J Allergy Clin Immunol 2004;113:101-8. 
15. Fregonese L, Swan FJ, van Schadewijk A, Dolhnikoff M, Santos MA, Daha MR, at al. Expression of the anaphylatoxin receptors C3aR and C5aR is increased in fatal asthma. J Allergy Clin Immunol 2005;115:1148-54.

16. Mauad T, Silva LF, Santos MA, Grinberg L, Bernardi FD, Martins MA, et al. Abnormal alveolar attachments with decreased elastic fiber content in distal lung in fatal asthma. Am J Respir Crit Care Med 2004;170:857-62.

17. Gelb AF, Zamel N, Hogg JC, Muller NL, Schein MJ. Pseudophysiologic emphysema resulting from severe small airway disease. Am J Respir Crit Care Med 1998;158:815-9.

18. Hogg JC, Chu F, Utokaparch S, Woods R, Elliott WM, Buzatu L, et al. The nature of small-airway obstruction in chronic obstructive pulmonary disease. N Engl J Med 2004;350:2645-53.

19. Image-Pro Plus reference guide for windows, Version 4.1, Media Cybernetics, L.P. Silver Spring, MD, 1999. p. 2-391.

20. Gooneratne NS, Patel NP, Corcoran A. Chronic obstructive pulmonary disease diagnosis and management in older adults. J Am Geriatr Soc 2010;1153-62.

21. Gibson PG, McDonald VM, Marks GB. Asthma in older adults. Lancet 2010;376:803-13.

22. Verbeken EK, Cauberghs M, Mertens I, Clement J, Lauweryns JM, Van de Woestijne KP. The senile lung. Comparison with normal and emphysematous lungs. 1. Structural aspects. Chest 1992;101:793-9. 
23. Bai T, Cooper J, Koelmeyer T, Pare PD, Weir TD. The effect of age and duration of disease on airway structure in fatal asthma. Am J Respir Crit Care Med 2000;162:663-9.

24. Hogg JC, McDonough JE, Gosselink JV, Hayashi S. What drives the peripheral lung-remodeling process in chronic obstructive pulmonary disease? Proc Am Thorac Soc 2009;6:668-72.

25. Bourdin A, Neveu D, Vachier I, Paganin F, Godard P, Chanez P. Specificity of basement membrane thickening in severe asthma. J Allergy Clin Immunol 2007 119:1367-74.

26. Liesker JJ, Ten Hacken NH, Zeinstra-Smith M, Rutgers SR, Postma DS, Timens W. Reticular basement membrane in asthma and COPD: similar thickness, yet different composition. Int $\mathrm{J}$ Chron Obstruct Pulmon Dis 2009;4:127-35.

27. Fabbri LM, Romagnoli M, Corbetta L, Casoni G, Busljetic K, Turato G, at al. Differences in airway inflammation in patients with fixed airflow obstruction due to asthma or chronic obstructive pulmonary disease. Am J Respir Crit Care Med 2003;167:418-24.

28. O'Byrne PM. Cytokines or their antagonists for the treatment of asthma. Chest 2006;130:244-50.

29. Bourdin A, Serre I, Flamme H, Vic P, Neveu D, Aubas P, at al. Can endobronchial biopsy analysis be recommended to discriminate between asthma and COPD in routine practice? Thorax 2004;59:488-93. 
30. Benayoun L, Druilhe A, Dombret MC, Aubier M, Pretolani M. Airway structural alterations selectively associated with severe asthma. Am J Respir Crit Care Med 2003;167:1360-8.

31. Alvarez GG, Schulzer M, Jung D, Fitzgerald JM. A systematic review of risk factors associated with near-fatal and fatal asthma. Can Respir $\mathrm{J}$ 2005;12:265-70.

32. Diette GB, Krishnan JA, Dominici F, Haponik E, Skinner EA, Steinwachs $D$, et al. Asthma in older patients. factors associated with hospitalization. Arch Intern Med 2002;162:1123-32 . 